InDreet

1.2021

Clàudia Gimeno Fernández

Universitat de València-Estudi

General

\section{Las disposiciones derogatorias indeterminadas en el ordenamiento jurídico español}

\begin{abstract}
Sumario
Las disposiciones derogatorias indeterminadas, entendidas como aquellas que no incluyen una enumeración cerrada de las normas que derogan, se encuentran presentes en una gran cantidad de las normas aprobadas en España. Estas han sido reiteradamente criticadas por nuestros tribunales, los dictámenes del Consejo de Estado y nuestra doctrina, que entienden que un mejor estudio del contexto normativo y una mayor concreción del ámbito de derogación de las normas es deseable y, además, posible. En este trabajo se realiza un estudio sistemático de las mismas con la finalidad de sistematizar el tratamiento jurídico que reciben en nuestro derecho, cuantificar su uso y, en especial, analizar los distintos problemas que surgen como consecuencia de su existencia.
\end{abstract}

\begin{abstract}
Undetermined derogatory provisions, understood as those that do not include a closed list of the rules they affect, are present in a large number of the regulations passed in Spain. They have been repeatedly criticized by our courts, the State Council's rulings, and the legal scholarship, which believe that a better study of the normative context and a greater specification of the derogation's scope is desirable and, even more, possible. In this article, we carry out a systematic study of these provisions with the aim of systematising their legal regime, quantifying their use and, especially, analysing the various problems that arise as a result of their existence.
\end{abstract}

Title: Considerations regarding the existence of undetermined derogatory provisions

Palabras clave: derogación indeterminada, derogación tácita, derogación expresa, seguridad jurídica, técnica legislativa

Keywords: indeterminate repeal, implied repeal, express repeal, legal certainty, legislative technique

DOI: $10.31009 /$ InDret.2021.i1.11 


\section{InDret}

1.2021

Recepción

27/11/2020

Aceptación

$30 / 12 / 2020$

\section{Índice}

1. Introducción

2. Tratamiento jurídico

2.1. Concepto y tipos de cláusulas

2.2. Antecedentes normativos

2.3. Regulación actual

2.4. La crítica a estas disposiciones en los dictámenes del Consejo de Estado

3. Cuantificación y evolución en el uso de las cláusulas derogatorias indeterminadas

4. Los problemas de las disposiciones derogatorias indeterminadas

4.1. La afectación de los principios de seguridad jurídica y de publicidad de las normas

4.2. La controvertida naturaleza de los efectos de estas cláusulas

4.3. La realidad alternativa

4.4. Su interpretación: ¿cuándo se entiende derogada una norma no derogada expresamente?

a. La no presunción de la derogación

b. Los requisitos de incompatibilidad

c. El juego de los principios de temporalidad, especialidad y jerarquía

5. Conclusiones

6. Bibliografía

Anexo. Cuantificación del uso de las cláusulas derogatorias indeterminadas

Este trabajo se publica con una licencia Creative Commons ReconocimientoNo Comercial 4.0 Internacional @) (1) ( ) 


\section{Introducción*}

Las disposiciones derogatorias indeterminadas pueden ser entendidas como aquellos enunciados normativos derogatorios que se limitan a fijar su objeto de manera abstracta, sin concretar las disposiciones a que se refieren. Nos referimos a las cláusulas que presentan enunciados de contenido similar a "quedan derogadas cuantas disposiciones de igual o inferior rango se opongan a lo establecido en la presente” y también a aquellas que hacen referencia a alguna normativa concreta, aunque de un modo impreciso, como por ejemplo "quedan derogadas todas las disposiciones de la ley $x$ que se opongan a lo dispuesto en la presente ley" ${ }^{1}$.

Estas disposiciones (que, como ahora veremos, no son infrecuentes) presentan multitud de problemas vinculados, en esencia, a su falta de claridad y a lo difícil de su interpretación, al no establecer de una forma evidente la afectación de la nueva norma respecto de las ya existentes en el ordenamiento jurídico ${ }^{2}$. Pero es que, además de suponer un ejemplo de una pobre técnica regulatoria, generan, por lo habitual, una incoherencia o inconsistencia normativa que deja en manos de la persona encargada de aplicar el derecho la tarea de detectarla y, posteriormente, dar preferencia a una norma frente a la otra ${ }^{3}$. Teóricamente esta operación es sencilla: cuando es evidente la incompatibilidad de un precepto de una norma anterior con uno de la posterior que incluye, a su vez, una cláusula de este tipo, se deberá de inaplicar (y tener por derogado) dicho precepto, y atribuir a tal cambio normativo las consecuencias que se consideren oportunas. Sin embargo, esta no es siempre una operación tan simple. Muchas veces no hay una incompatibilidad grave o irresoluble entre ambas normas, o esta se basa en una oposición entre los fines de la nueva norma con la anterior o en nuevos preceptos que, por razones de sistemática, cambian el significado de los anteriores.

\footnotetext{
* La presente investigación se ha beneficiado de las ayudas para la contratación de personal investigador en formación de carácter predoctoral correspondientes al año 2018 del Vicerrectorado de Investigación y Política Científica de la Universitat de València-Estudi General. La autora agradece las correcciones y sugerencias aportadas por los Profs. Andrés Boix Palop y Gabriel Doménech Pascual.

${ }^{1}$ En este sentido, Luis. M. ${ }^{a}$ Díez-Picazo Giménez (1990), La derogación de las leyes, Civitas, Madrid; Riccardo GuAstini, (1987) “In tema di abrogazione”, en Claudio LuZZATI (coord.) L'abrogazione delle leggi. Un dibattito analítico, 1987, Giuffrè, Milán; Marina GASCÓN ABELLÁN (1994), "Cuestiones sobre la derogación”, DOXA, 15-16, págs. 845-859; Josep AGUiLÓ Regla (1994), “La derogación en pocas palabras”, Anuario de Filosofía del Derecho, XI, págs. 407-418; y Alessandro ANDronio (1997), "Peculiarità nei fenómeno abrogativi pel periodo più recente”, págs. 109-137, en Ugo DE SIERVo (coord.), Osservatorio sulle fonti, Torino.

${ }^{2}$ La importancia de la claridad de las normas ha sido puesta de manifiesto de forma constante por numerosas organizaciones internacionales, especialmente la OCDE, y la doctrina. En este sentido, como Juan S. Mora-SAnguinetTi (2019), "La "complejidad" de la regulación española ¿cómo medirla? ¿qué impacto económico tiene?”, Información Comercial Española: Revista de Economía, 907, págs. 145-162 (p. 155 ) indica, se han propuesto diversas maneras de medir la ambigüedad (o la falta de la claridad) de las normas, entre las que destaca Bernhard WALtL y Florian MATTHES (2014), "Towards Measures of Complexity: Applying Structural and Linguistic Metrics to German Laws", Jurix: International Conference on Legal Knowledge and Information Systems, Krakow; estudio en el que se analizan las interrelaciones de una norma con las demás del sistema jurídico con la finalidad de determinar su comprensibilidad y claridad.

${ }^{3}$ Aguiló Regla (1994).
} 
Encontrarnos ante el fenómeno de la derogación indeterminada supone así confrontar todos y cada uno de los enunciados de la ley en la que está incluida esta disposición con el resto de enunciados (de igual o inferior rango) del ordenamiento jurídico para determinar si se da alguna contradicción entre enunciados jurídicos. Detectada la existencia de enunciados contradictorios, serán jueces y tribunales (o cualquier otra persona encargada de la aplicación del derecho), quienes tendrán que aplicar uno de los enunciados en conflicto ${ }^{4}$. Pero hay que tener también en cuenta que esta solución siempre será fragmentaria: la resolución judicial será ad casum, con carácter general, y, por tanto, la inaplicación normativa por esta causa no tendrá efectos erga omnes. Por lo que no podemos afirmar "que de esta forma se contribuya a perseguir la certeza y no la confusión normativa, tratando de hacer factible que tanto los ciudadanos como los aplicadores del derecho sepan a qué atenerse” ${ }^{5}$.

Con la finalidad de realizar un estudio omnicomprensivo de las cláusulas derogatorias indeterminadas, procederemos a analizar, en primer lugar, el tratamiento jurídico que reciben en nuestro derecho. Posteriormente, realizaremos una cuantificación del fenómeno para así poder adentrarnos, a continuación, en el examen de los distintos problemas que presentan las disposiciones derogatorias indeterminadas en relación con los principios constitucionales de seguridad jurídica y de publicidad de las normas, la controvertida naturaleza de los efectos que su inclusión supone y su razón de ser. Finalmente, analizaremos cómo jurisprudencia y doctrina han resuelto los conflictos generados por la existencia de este tipo de preceptos normativos.

\section{Tratamiento jurídico}

\subsection{Concepto y tipos de cláusulas}

En la sistematización de la tipología de las cláusulas derogatorias existentes tiene una gran influencia la tradicional diferenciación entre derogación expresa y tácita. La derogación expresa se ha definido como aquella en la que la cesación de la vigencia de las normas opera por la introducción de una disposición en el nuevo texto legal cuya función es decretar la derogación de una o varias normas -enumeradas expresamente o no en dicha disposición-. Por su parte, la tácita, que siempre ha tenido una naturaleza mucho más controvertida, es la que opera en aquellos casos en que la nueva regulación no incluye cláusula derogatoria, pero se produce en un sistema en el que existe una norma sobre la producción jurídica que establece dicho efecto derogatorio ${ }^{6}$. Esta última comprende tanto aquellos casos en los que se da una

\footnotetext{
${ }^{4}$ Victoria ITURRALDE SeSMa (2002), “Derogación innominada, acto de habla y de satisfacción condiciones”, Anuario de Filosofía del Derecho, 19, págs. 357-375. En este sentido, son además de especial interés los reparos formulados por DíEz-PiCAzo GimÉnEz (1990, p. 332 y ss.) a la posibilidad de dejar en manos del intérprete jurídico una cuestión que, por su relevancia, debería ser resuelta por el legislador en atención a los límites constitucionales de la potestad jurisdiccional ex art. 117 CE.

5 Tomás Vidal Martín (2013), “Técnica legislativa, inserción de la norma en el ordenamiento jurídico y Tribunal Constitucional”, Teoría y Realidad Constitucional, 31, págs. 323-350, (p. 340).

${ }^{6}$ Nos referimos, en el caso del derecho español, a lo previsto por el art. 2.2 del Código Civil, que tiene como fundamento el principio de temporalidad o cronología de las normas (lex posterior derogat legi priori), que ha sido considerado por nuestra doctrina, conjuntamente con el de especialidad normativa y el
} 
nueva regulación integral de la materia como cuando una norma posterior resulta incompatible con otra anterior.

A medio camino entre ambas encontramos las cláusulas derogatorias que no concretan las disposiciones a las que se refieren. Es decir, aquellas que, pese a ser verdaderas disposiciones derogatorias de otras normas, no incluyen una enumeración cerrada de estas, sino que remiten a un momento posterior al de la aprobación de dicha norma la determinación de la existencia de una contradicción y, por consiguiente, su efecto derogatorio. $Y$ es que, si bien de conformidad con la descripción indicada anteriormente deben adjudicarse de lleno al fenómeno de la derogación expresa, su falta de claridad y sus discutibles efectos sobre las normas que afectan han llevado en ocasiones a jurisprudencia y doctrina (como veremos más adelante) a entenderlas subsumidas en el fenómeno de la derogación tácita. Es por ello por lo que, con la finalidad de centrarnos en ellas y tratar de clarificar su régimen jurídico, a los efectos del presente trabajo sistematizaremos las disposiciones derogatorias de la siguiente manera: distinguiremos entre las cláusulas derogatorias determinadas, esto es, aquellas que no exigen interpretación alguna para saber si hay derogación o no y en las que la norma expresamente identifica qué normas o apartados de estas quedan derogados desde su entrada en vigor (por ejemplo, mediante una indicación como "queda derogado el capítulo $X$ de la ley $Y$ " o "queda derogada la ley $Y^{\prime \prime}$ ); y las cláusulas derogatorias indeterminadas, caracterizadas por exigir, aunque sea mínima, una interpretación para saber si hay o no derogación en relación con un concreto enunciado normativo. Un término medio entre ambas lo encontraríamos en las que podrían definirse como cláusulas derogatorias mixtas: aquellas que contienen cláusulas del tipo "se derogan las leyes $x$ e $y$ en todo lo que se opongan a la presente norma" o "se derogan las normas $x$ e $y$, así como cualquier otra disposición que no sea compatible con la presente norma”.

Estas cláusulas suponen, en algunos casos, un verdadero intento por circunscribir con la mayor concreción posible las normas que van a quedar derogadas y en ellas la inclusión de la cláusula indeterminada es accesoria. Sin embargo, en muchas otras ocasiones, evidencian carencias en el estudio realizado durante la elaboración del texto normativo de las contradicciones generadas por la nueva norma, que se tratan de parchear con la identificación de aquellas normas que de un modo más evidente van a tener que derogarse por la nueva regulación y la introducción de esta cláusula de derogación genérica. Es por este último motivo, así como por el hecho de que, en cualquier caso, exigen una mínima interpretación de su contenido para detraer sus efectos derogatorios, que a los efectos de nuestro análisis las entenderemos comprendidas dentro del fenómeno de las cláusulas derogatorias indeterminadas -sin perjuicio de que, allá donde corresponda, realicemos alguna puntualización a su respecto-.

\subsection{Antecedentes normativos}

de jerarquía, un principio general del derecho y, a su vez, un criterio de solución de antinomias jurídicas (L. M. ${ }^{a}$ Díez-Picazo Giménez, 1990). En este sentido, José Antonio TARDío PATO (2003), "El principio de especialidad normativa (lex specialis) y sus aplicaciones jurisprudenciales”, Revista de Administración Pública, 162, págs. 189-225 (p. 189). 
La exigencia de una racionalización de las cláusulas derogatorias, cuyas ineficiencias parece que ya habían sido detectadas en el siglo pasado ${ }^{7}$, ha comportado la necesidad de incorporar previsiones específicas en los manuales de técnica legislativa que sucesivamente se han aprobado en nuestro país ${ }^{8}$. En este sentido, fue por primera vez en los años noventa que se aprobaron una serie de instrucciones que habían de ser tenidas en cuenta en la elaboración de las leyes. Estas fueron las Directrices sobre la forma y estructura de los anteproyectos, aprobadas por Acuerdo del Consejo de Ministros de 18 de octubre de 1991. En ellas se establecían las características formales y técnicas que habrían de reunir los anteproyectos normativos e introducían la obligación de incluir una relación de las normas que se derogaban y de las que se mantenían en vigor. Asimismo, pese a que preveían la posibilidad de incluir una cláusula general de salvaguardia (es decir, una cláusula derogatoria indeterminada), exigían que esta acotase la materia sobre la que operaban -sin ser aceptables, por tanto, cláusulas genéricas sobre la derogación de, en general, todo precepto que se opusiera a la norma en cuestión- (Directriz 25).

Estas primeras directrices fueron derogadas por las Directrices de Técnica Normativa aprobadas por el Acuerdo de Consejo de Ministros de 22 de julio de $2005^{9}$, que son todavía aplicables a los anteproyectos de ley, proyectos de real decreto legislativo, de real decreto-ley y de real decreto,

\footnotetext{
${ }^{7}$ El artículo 129.3 de la Ley de Procedimiento Administrativo de 1958 ya prohibía formular una propuesta de disposición de carácter general o de anteproyecto de Ley sin que al proyecto normativo se acompañase una "tabla de vigencias de disposiciones anteriores sobre la misma materia" y sin que se consignasen expresamente las anteriores normas que hubiesen de quedar total o parcialmente derogadas. Sin embargo, dicho precepto fue incumplido de manera sistemática, sin que este extremo fuese considerado una irregularidad invalidante del procedimiento, tal y como indica Gabriel DoMÉNECH PASCUAL (2002), La invalidez de los reglamentos, Tirant Lo Blanch, València, quien además indica que, pese a que esta ilegalidad debía conducir a la invalidez de los correspondientes reglamentos, el Tribunal Supremo ha considerado dicha omisión “absolutamente irrelevante”. En el procedimiento de elaboración reglamentaria previsto por la Ley 50/1997, de 27 de noviembre, del Gobierno, se eliminó definitivamente la obligación de elaborar una tabla de vigencias.

${ }^{8}$ Las políticas de calidad normativa se han implementado de manera poco sistemática en España y siempre al rebufo de las desarrolladas en el seno de la UE y otros países desarrollados de nuestro entorno, como Alemania, Francia, el Reino Unido o los Estados Unidos. Estas engloban el análisis de cuestiones de carácter tanto formal o técnico -como las que abordamos en este estudio-, como sustantivo o material, más relacionadas con los principios de adecuación, necesidad y proporcionalidad de las normas. Para un tratamiento en profundidad de las medidas de calidad normativa desarrolladas en España y los países de nuestro entorno, véanse Andrés Boix PALOP y Claudia Gimeno Fernández (2020), La mejora de la calidad normativa, PUV, València; Claudia GIMENo FERNÁNDEZ (2018), La qualitat normativa al País Valencià. Propostes per a un nou model de producció i avaluació de les nostres normes, Fundació Nexe, València, y Dolors Canals Ametller (ed.) (2016), Datos. Protección, Transparencia y Buena Regulación, Documenta Universitaria, así como la bibliografía en ellos citada.

${ }^{9}$ Esta nueva regulación es probable en parte venga motivada por la aprobación, en el seno de la UE, de los Acuerdos Interinstitucionales de 20 de diciembre de 1994, sobre un método de trabajo acelerado con vistas a la codificación oficial de los textos legislativos (DOUE de 4 de abril de 1996); de 22 de diciembre de 1998, relativo a las directrices comunes sobre la calidad de la redacción de la legislación comunitaria (DOUE de 17 de marzo de 1999); de 28 de noviembre de 2001, para un recurso más estructurado a la técnica de la refundición de los actos jurídicos (DOUE de 28 de noviembre de 2001); y de 16 de diciembre de 2003, “Legislar mejor” (DOUE de 31 de diciembre del 2003). En este aspecto, el Acuerdo de 1998 recoge la necesidad de que los actos y disposiciones que hayan quedado obsoletos sean objeto de derogación expresa, y que la adopción de cualquier nuevo acto deba dar lugar a la derogación expresa de cuantos actos o disposiciones resulten inaplicables o superfluos como consecuencia del nuevo acto (directriz 21).
} 
propuestas de acuerdo del Consejo de Ministros y, en todo lo que sea posible, a las disposiciones y actos administrativos de los órganos de la Administración General del Estado que se publiquen en el BOE. En relación con las disposiciones derogatorias, estas nuevas directrices indican que estas deberán ser precisas y expresas y que se evitarán las cláusulas genéricas de derogación, "que en ningún caso pueden sustituir a la propia enunciación de las normas derogadas”. Asimismo, afirman la inconveniencia de mantener vigentes normas con idéntico ámbito de aplicación, ordenando la realización de una tarea de integración de los preceptos que quiera mantener vigentes en la nueva norma aprobada, con la finalidad de evitar cualquier tipo de indeterminación sobre la vigencia o no de una disposición (Directriz 41) ${ }^{10}$.

Posteriormente, los trabajos para la transposición de la Directiva de Servicios ${ }^{11}$ contribuyeron a la extensión de algunos principios e instrumentos relacionados con la calidad normativa, que cristalizaron en la aprobación de las Leyes 17/2009, de 23 de noviembre, sobre el libre acceso a las actividades de servicios y su ejercicio ${ }^{12}$ y $2 / 2011$, de 4 de marzo, de Economía Sostenible ${ }^{13}$. Sin embargo, el carácter meramente programático de esta regulación las relegó, en este aspecto, a meros criterios orientadores.

\subsection{Regulación actual}

El desarrollo del Programa de Garantía de la Unidad de Mercado, en mayo de 2012, y la creación de la Comisión de Reforma de las Administraciones Públicas (CORA), se convirtieron en motores de una nueva legislación básica del procedimiento administrativo. Así, tras el Informe sobre la reforma de las Administraciones Públicas elaborado por la CORA, que subrayó que uno de los motivos que habían reducido la comprensión y la seguridad de los textos legislativos era “la ausencia de una lista exhaustiva de los artículos y leyes que deroga la nueva regulación”"14,

\footnotetext{
${ }^{10} \mathrm{Al}$ respecto, el dictamen del Consejo de Estado núm. 621/2004, de 20 de mayo, sobre el Proyecto de Acuerdo por el que se aprueban las Directrices de técnica normativa, indica que "el Consejo de Estado viene encareciendo, en aras de la seguridad jurídica, que las disposiciones derogatorias permitan conocer con alguna certeza cuál es la legislación vigente, indicándose las disposiciones que a partir de la nueva norma van a resultar total o parcialmente derogadas (así, el reciente dictamen 882/2004). [...] Por ello, debería hacerse referencia a la conveniencia de evitar disposiciones derogatorias genéricas que no identifican a las que son objeto de derogación y, en todo caso, eliminarse de la directriz 45 la disposición derogatoria “tipo" que consiste, precisamente, en una cláusula general. Una tal cláusula puede servir adecuadamente de cierre, respecto de una materia, a una derogación expresa formulada en términos claros y concretos, pero no sustituir, a todo evento, a la propia enunciación de las normas derogadas”.

${ }^{11}$ Directiva 2006/123/CE del Parlamento Europeo y del Consejo, de 12 de diciembre de 2006, relativa a los servicios en el mercado interior.

${ }^{12}$ La Ley 17/2009, de 23 de noviembre creó el Comité para la mejora de la regulación de las actividades de servicios e introdujo por primera vez una serie obligaciones vinculadas con el cumplimiento de los principios de mejora regulatoria.

13 La Ley 2/2011, mediante el desarrollo de los principios de necesidad, proporcionalidad, seguridad jurídica, transparencia, accesibilidad y eficacia trató de cumplir con los compromisos europeos en materia de Better Regulation y aportó una base sólida para aunar los progresos tímidos que hasta ahora venía realizando España en este ámbito. En este sentido, véase Pedro Mercado PACHeco (2013), "Calidad de la Ley, Evaluación de Impacto Normativo y Argumentos Económicos”, Anales de la Cátedra Francisco Suárez, 47, págs. 85-108.

${ }^{14}$ El desarrollo de los trabajos de la CORA dio lugar a la elaboración de un informe que se presentó al Consejo de Ministros el 21 de junio de 2013, con 218 medidas para la reforma de la estructura y el
} 
se aprobaron las Leyes 39/2015 de Procedimiento Administrativo Común de las Administraciones Públicas (LPACAP) y 40/2015, de 1 de octubre, de Régimen Jurídico del Sector Público (LRJSP), que dejan traslucir cierta preocupación por la cuestión al incluir previsiones que, de algún modo, influyen sobre la regulación de las cláusulas derogatorias.

La LRJSP, en su disposición final tercera, por la que modifica la Ley 50/1997, de 27 de noviembre, del Gobierno, atribuye al Ministerio de la Presidencia, con el objeto de asegurar la coordinación y la calidad de la actividad normativa del Gobierno, el análisis de la necesidad de incluir la derogación expresa de las normas, así como de refundir en la nueva otras existentes en el mismo ámbito (art. 26.9 de la Ley del Gobierno). De similar forma, el Real Decreto 931/2017, de 27 de octubre, por el que se regula la Memoria del Análisis de Impacto Normativo, aprobado en desarrollo de esta modificación de la Ley del Gobierno ${ }^{15}$, también prevé la necesidad de que la memoria del análisis de impacto normativo a realizar por parte del Gobierno central en los trámites de elaboración de los anteproyectos de ley, de los proyectos de real decreto legislativo y de normas reglamentarias incluya un listado pormenorizado de las normas que quedarán derogadas (art. 2.1.b) ${ }^{16}$.

La LPACAP, por su parte, introduce en su título VI, sobre iniciativa legislativa y potestad reglamentaria de las Administraciones Públicas, por primera vez en España unas bases para lograr una mejora de los procedimientos regulatorios ${ }^{17}$. Este título se organiza en torno a los principios de buena regulación (art. 129 LPACAP), el impulso de la participación ciudadana (art. 133.1 y 2 LPACAP), y el desarrollo de instrumentos de evaluación ex ante (art. 132 LPACAP) y ex post de las normas (art. 130 LPACAP) ${ }^{18}$. Entre todas estas previsiones, destaca, a

funcionamiento de las Administraciones Públicas en España. El informe se encuentra accesible en: http://transparencia.gob.es/transparencia/dam/jcr:b1c69477-9882-41a5-9f6d-5cbb46fa12b4/reformaAAPP.pdf (último acceso: 25 de noviembre de 2020).

${ }^{15}$ En realidad, el Real Decreto 931/2017 no supone ninguna innovación jurídica al respecto, ya que el Real Decreto 1083/2009, de 3 de julio, por el que se regula la memoria del análisis de impacto normativo, que sustituye, ya preveía la necesidad de que las memorias, estudios e informes que se contemplan en los arts. 22.2 y 24.1.a) y 24.1.b) de la Ley 50/1997 se incluyesen en un único documento denominado "Memoria del análisis de impacto normativo", a redactar por parte del órgano o centro directivo proponente del proyecto normativo de forma simultánea a la elaboración de este, y que este documento debía de contener un apartado relativo al contenido y análisis jurídico de la norma que incluyese el listado pormenorizado de las normas que quedarán derogadas como consecuencia de la entrada en vigor de la misma [art. 2.1. b)].

${ }^{16}$ Sin embargo, tal y como se indica por algunos miembros de la Oficina de coordinación y calidad normativa (que, desde 2018, es el órgano encargado de supervisar la corrección de los análisis de impacto normativo) en Ramón SÁNCHEZ-PuENTE, Fe BuENo RodríguEZ y Andrea GARCíA VIDAL (2019), "La evaluación ex ante. Una visión de la Oficina de coordinación y calidad normativa”, Información Comercial Española, págs. 23-36, en general, en las memorias se presta poca atención a este aspecto, ya que no se identifican de forma precisa las normas derogadas con la finalidad de evitar que el proceso de innovación normativa dé lugar a una situación de inseguridad jurídica. En este sentido, concluyen que "(s)in hacer previamente el esfuerzo de determinar en cada caso qué normas deroga la nueva norma, no será posible la tan demandada simplificación normativa" (p. 32).

17 Ricardo Almeida González (julio de 2016), Red Internacional de Evaluación de Políticas Públicas. Obtenido de La Calidad Normativa y la nueva Ley de Procedimiento Administrativo en España: https://www.redinternacionalevaluacion.com/ricardo-almeida-leyes.

18 Juan Alfonso SANTAMARÍA PASTOR (2016), “Un nuevo modelo de ejercicio de las potestades administrativas”, Revista Española de Derecho Administrativo, 175, es muy crítico con la regulación 
los efectos del presente estudio, el desarrollo expreso del principio de seguridad jurídica, que implica que la iniciativa normativa se ejercerá de manera coherente con el resto del ordenamiento jurídico para generar un marco normativo estable, predecible, integrado, claro y de certidumbre, que facilite su conocimiento y comprensión (art. 129.4 LPACAP).

En relación con este principio, igual que respecto de los demás enumerados, habrá de estarse tanto a la aplicación y desarrollo de los mismos por parte de las Administraciones Públicas ${ }^{19}$ como a la posible revisión judicial del cumplimiento con los mismos. Al respecto se señala que, siempre que se establecen principios que han de seguirse en una determinada materia se plantea el problema de su eficacia práctica, es decir, ¿podrá impugnarse ante los tribunales un reglamento, por ejemplo, por no respetar el principio de seguridad jurídica o por no ser la derogación indeterminada el instrumento más adecuado para alcanzar los fines perseguidos? ${ }^{20}$ En nuestra opinión, la respuesta ha de ser afirmativa -más aún si tenemos en cuenta que la LPACAP establece que en la exposición de motivos o en el preámbulo, según se trate, respectivamente, de anteproyectos de ley o de proyectos de reglamento, deberá quedar suficientemente justificada la adecuación de la norma a dichos principios- ${ }^{21}$, con independencia de la mayor o menor dificultad que represente la prueba ante los tribunales de que un reglamento ha infringido alguno de esos principios de buena regulación, y si esta

introducida en este Título de la LPACAP, lo que se demuestra con afirmaciones como “(l)a regulación de los temas objeto de este estudio se inicia con un precepto (art. 127 LPAC) del que lo mejor que puede decirse es que es absolutamente innecesario. Bajo el rótulo "Iniciativa legislativa y potestad para dictar normas con rango de ley" se inserta un conjunto de previsiones obvias, relativas a la titularidad del poder de elevar proyectos de ley a las Cámaras y de aprobar decretos-leyes y decretos legislativos, que se limitan a reproducir mandatos constitucionales y estatutarios harto conocidos, y que el legislador bien pudiera haberse ahorrado".

${ }^{19}$ A pesar de la vocación de generalidad de las medidas introducidas a través de la LPACAP, aplicables $a$ priori a todas las Administraciones Públicas, el carácter básico de estas previsiones ha sido declarado inconstitucional por parte del Tribunal Constitucional en Sentencia 55/2018 de 24 de mayo, por ser contrarias al orden constitucional y, por tanto, no son aplicables a las Comunidades Autónomas. Antonio Eduardo EMBID TELLo (2019), "Calidad normativa y evaluación ex-post de las normas jurídicas”, Revista General de Derecho Administrativo, 50, se muestra crítico con que un Título de una norma cuya finalidad es aumentar "la seguridad jurídica y la predictibilidad del ordenamiento" regule un ciclo normativo "de forma desordenada, sin atender a la progresión temporal de los trámites, y que además es declarado inconstitucional a los pocos años, deviniendo su contenido residual repetitivo con lo dispuesto ya en otra Ley, es quizás una pésima forma de ordenar la calidad normativa”.

20 En este sentido, José Ramón Rodríguez Carbajo (2015), “El Proyecto de Ley del Procedimiento Administrativo Común de las Administraciones Públicas (la ley del procedimiento electrónico)”, Actualidad Administrativa, 10.

${ }^{21}$ En este sentido, SANTAMARÍA PASTOR (2016) incide en la importancia de este mandato de la LPACAP, que "supone un rasgo de valentía y la asunción de un riesgo considerable, en cuanto proporciona a los tribunales contenciosos un potentísimo instrumento para hacer efectivos estos principios, procediendo a la anulación de las normas reglamentarias que carezcan total o parcialmente de esta justificación en su preámbulo. Y no solo eso: el efectivo cumplimiento de estos principios (dado que nada permite afirmar que no tengan carácter jurídicamente vinculante) no puede satisfacerse meramente con la redacción de unos preámbulos algo más detallados que aludan a la observancia de su contenido. No basta, pues, con razonar que la norma aprobada sea necesaria, eficaz, proporcionada, accesible, eficiente y que proporciona seguridad jurídica a sus destinatarios: es necesario que el contenido de la misma responda realmente a estos calificativos, lo cual abre unas posibilidades indefinidas de estructurar argumentos impugnatorios de las mismas en el marco de un recurso directo o indirecto contra ella... y también de que los tribunales entren a realizar idénticas valoraciones y anulen, en su caso, los preceptos impugnados”. 
situación se diera nos encontraríamos ante un reglamento nulo por ser contrario a la LPACAP. A favor de esta tesis, además, encontramos la creciente aplicación de la regla de la nulidad de pleno derecho en los casos de impugnación de normas reglamentarias por cuestiones formales y defectos procedimentales ${ }^{22}$, que demuestra que la tradicional deferencia de los tribunales hacia los productos normativos de la Administración está empezando a ser sustituida por una actitud mucho más decidida y osada, que supone la utilización cada vez en más casos de estos principios como parámetros de control de la legalidad de las normas ${ }^{23}$. Sin embargo, no podemos dejar de reconocer la contradicción en la que se incurriría en casos como este en que, en aras a mejorar la seguridad jurídica en el ordenamiento jurídico se plantease una solución -la invalidez de la norma que no presenta una cláusula de derogación precisa- que todavía tendría más incidencia en dicha seguridad jurídica que la que supondría el problema inicial ${ }^{24}$.

\subsection{La crítica a estas disposiciones en los dictámenes del Consejo de Estado}

Las cláusulas derogatorias indeterminadas no han pasado inadvertidas tampoco en el análisis de las normas que realiza de ordinario el Consejo de Estado. Este, desde su posición de supremo órgano consultivo del Gobierno ha manifestado en numerosas ocasiones las confusiones que estas cláusulas pueden conllevar y ha criticado su uso de manera reiterada, aunque quizás se le pueda reprochar cierta falta de consistencia al respecto ${ }^{25}$.

\footnotetext{
${ }^{22}$ La desproporción entre las consecuencias de la declaración de nulidad de estas disposiciones de carácter general y el desvalor producido por la infracción de estos vicios procedimentales ha causado cierta preocupación en nuestra doctrina, que se ha pronunciado en numerosas ocasiones a favor de soluciones intermedias. En este sentido, véanse Fernando LóPEZ RAMÓN (2018), "La calificación de los vicios de los reglamentos", Revista de Administración Pública, 205, págs. 13-48, así como los artículos integrantes de la Sección Debates (Seminario Sala de lo Contencioso-Administrativo del Tribunal Supremo - Revista de Administración Pública) del número 210, Septiembre/Diciembre de 2019, de la Revista de Administración Pública, dedicado en exclusiva al estudio de esta cuestión.

${ }^{23}$ Así lo anticipó, además, SANTAMARía PASTOR (2016) al afirmar que “(l)o más probable es que este ambicioso acervo principial sea utilizado solo, como instrumento de control judicial, en casos extremos de vulneración de su contenido; pero, aun así, la conversión por las partes de un debate jurídico en otro político o de oportunidad es algo que sucederá con seguridad casi absoluta a partir del momento en que una sentencia especialmente valiente haga el disparo de salida, anule un reglamento en aplicación de este artículo y su fallo sea jaleado en las revistas jurídicas; lo que también ocurrirá, porque las normas hoy vigentes que desconocen manifiestamente estos principios se cuentan por millares".

${ }^{24}$ En relación con la aplicación de la perspectiva económica a la determinación de si un acto irregular se ha de considerar válido o inválido son de gran interés las observaciones de Gabriel DomÉNECH PASCUAL (2017), "Las irregularidades no invalidantes desde una perspectiva económica", págs. 151-170, en Fernando López Ramón y Francisco VIllar Rojas (coords.), El alcance de la invalidez de la actuación administrativa: actas del XII Congreso de la Asociación Española de Profesores de Derecho Administrativo, Instituto Nacional de Administración Pública, Madrid, según el cual “un acto irregular merece ser válido si esta es la solución que satisface efectivamente en mayor medida el conjunto de los principios jurídicos implicados, es decir, de los fines considerados valiosos por la sociedad y que constituyen el fundamento del ordenamiento jurídico" (p. 154).

${ }^{25}$ En la mayoría de sus dictámenes el Consejo de Estado pasa por encima de la cuestión de la conveniencia de sustituir la cláusula derogatoria indeterminada por una determinada, aceptando sin más este tipo de cláusulas. Incluso puede detectarse algún caso en que el Consejo afea la inexistencia de una cláusula de derogación genérica en la norma como complemento de la cláusula expresa, como sucede en los dictámenes núm. 871/2015, de 29 de octubre y núm. 751/2017, de 14 de septiembre. También en el pasado ha llegado a excusar la no previsión de una cláusula de derogación expresa pese a venir impuesta, en ese momento, por el artículo 129.3 de la Ley de Procedimiento Administrativo de 1958 en atención a la "dificultad de determinar con precisión la normativa vigente en esta materia" (dictamen núm. 1246/1995,
} 
En este aspecto, son ilustrativos los dictámenes núm. 875/2013, de 26 de septiembre ${ }^{26}$, -en el que calificaba de "chatarra normativa”, a “estas normas que perviven (aquí ya como meros restos parciales de lo que fueron en su momento) por la simple inercia de su existencia en el ordenamiento jurídico y que solo contribuyen a la confusión y equívoco sobre el derecho vigente en cada momento"-, núm. 621/2004, sobre el Proyecto de Acuerdo por el que se aprueban las Directrices de técnica normativa -donde subrayaba la necesidad de introducir previsiones específicas a favor de este tipo de cláusulas (apunte que, como hemos visto anteriormente, se tuvo en cuenta a la hora de aprobar definitivamente estas Directrices)-, o el núm. 88/2011, de 17 de febrero, en relación con el Proyecto de Ley de Residuos y suelos contaminados, en el que indicó que "ese efecto derogatorio genérico ya opera directamente -sin necesidad de decir nada- a través del artículo 2.2 del Código Civil” y que "serviría mucho mejor a la obligada certidumbre de la norma aplicable el que se hubiera realizado un esfuerzo mucho más acabado (que además han solicitado multitud de intervinientes) sobre cuál sea exactamente el conjunto de preceptos de la Ley 11/1997 afectados por el futuro texto" ${ }^{27}$. Asimismo, el Consejo de Estado se ha pronunciado a favor de la derogación de las normas como consecuencia de la transposición de normativa europea en numerosas ocasiones ${ }^{28}$.

En conclusión, también el Consejo de Estado ha relacionado la seguridad jurídica y la mejor técnica con la presencia, en los textos normativos, de cláusulas derogatorias expresas y se ha mostrado partidario de la introducción de estas en nuestro ordenamiento jurídico. Asimismo, y teniendo en cuenta lo limitado de sus dictámenes, ha identificado y criticado la falta de exhaustividad de los análisis realizados por el gobierno para la tipificación de las normas a derogar, aspecto que a nuestro parecer es sintomático sobre la potencialidad real de mejora de las normas en este aspecto. Sin embargo, debe reconocerse la limitada influencia de sus

de 20 de julio, sobre el Proyecto Real Decreto por el que se fijan las líneas directrices para la evaluación de los aditivos en la alimentación animal). De cuanto hemos indicado puede deducirse que, por lo habitual, el Consejo de Estado es crítico con el uso de estas cláusulas cuando la incoherencia que se genera es del todo evidente, mientras que acepta su existencia cuando funcionan como apoyo de un precepto derogatorio determinado bien desarrollado.

${ }^{26}$ En relación con el Proyecto de Real Decreto por el que se establecen normas complementarias para la producción, designación, presentación y etiquetado de determinadas bebidas espirituosas. En este sentido, también, dictamen núm. 2030/2009, de 21 de enero de 2010, sobre el Proyecto de Real Decreto por el que se derogan disposiciones relativas al control oficial y criterios microbiológicos de los productos alimenticios, en el indicaba que "razones de seguridad jurídica aconsejan su derogación expresa para evitar problemas de interpretación. Se trata, en último término, de hacer efectivo el principio de seguridad jurídica eliminando del ordenamiento jurídico lo que se ha dado por llamar por este Consejo "chatarra normativa": "restos o conjuntos de normas en vigor cuyos contenidos y realidades sobre las que se proyectan han sido claramente superados, conviniendo simplemente su eliminación del sistema jurídico para facilitar la mejor comprensión y eficacia de éste" (dictamen núm. 2.146/2009, de 14 de enero de 2010)".

${ }^{27}$ Críticas a este tipo de cláusulas derogatorias, en atención a las posibles confusiones en relación con las normas aplicables, también se pueden encontrar en los dictámenes núm. 807/2018, de 4 de octubre; núm. 1116/2015, de 10 de marzo de 2016; núm. 1439/2013, de 6 de marzo de 2014; núm. 25/2008, núm. 99/2009, de 18 de marzo; núm. 800/2006, de 22 de junio; núm. 1045/2001, de 9 de mayo; y núm. 1361/1993, de 25 de noviembre, entre otros.

${ }^{28}$ En este sentido véanse, por ejemplo, los dictámenes núm. 48.700, de 29 de enero de 1986, y núm. $87 / 2020$, de 16 de abril. 
dictámenes, cuyas recomendaciones, en especial en este punto, no son siempre seguidas por el legislador a la hora de reformular y aprobar los textos normativos definitivos ${ }^{29}$.

\section{Cuantificación y evolución en el uso de las cláusulas derogatorias indeterminadas}

Como hemos comprobado, las directrices y normas aprobados recientemente, así como los dictámenes del Consejo de Estado, abogan de manera reiterada por el uso de las cláusulas derogatorias expresas como instrumento idóneo para conseguir una mayor seguridad jurídica. Ahora nos queda analizar si lo indicado en ellas ha sido seguido por el poder legislativo y el Gobierno a la hora de aprobar leyes o normas de rango reglamentario. Con esta finalidad, se ha analizado el porcentaje de normas estatales que contienen en su formulación disposiciones derogatorias indeterminadas sobre el total de normas aprobadas que contienen cualquier tipo de cláusula derogatoria (puesto que hay numerosas normas que no las contienen, como por ejemplo, aquellas que introducen una regulación ex novo de una materia), según la tipología de norma, y la evolución en uso de estas en los últimos 20 años, es decir, el período que va desde el año 1999 hasta $2019^{30}$. Lo sistematizamos en la siguiente tabla.

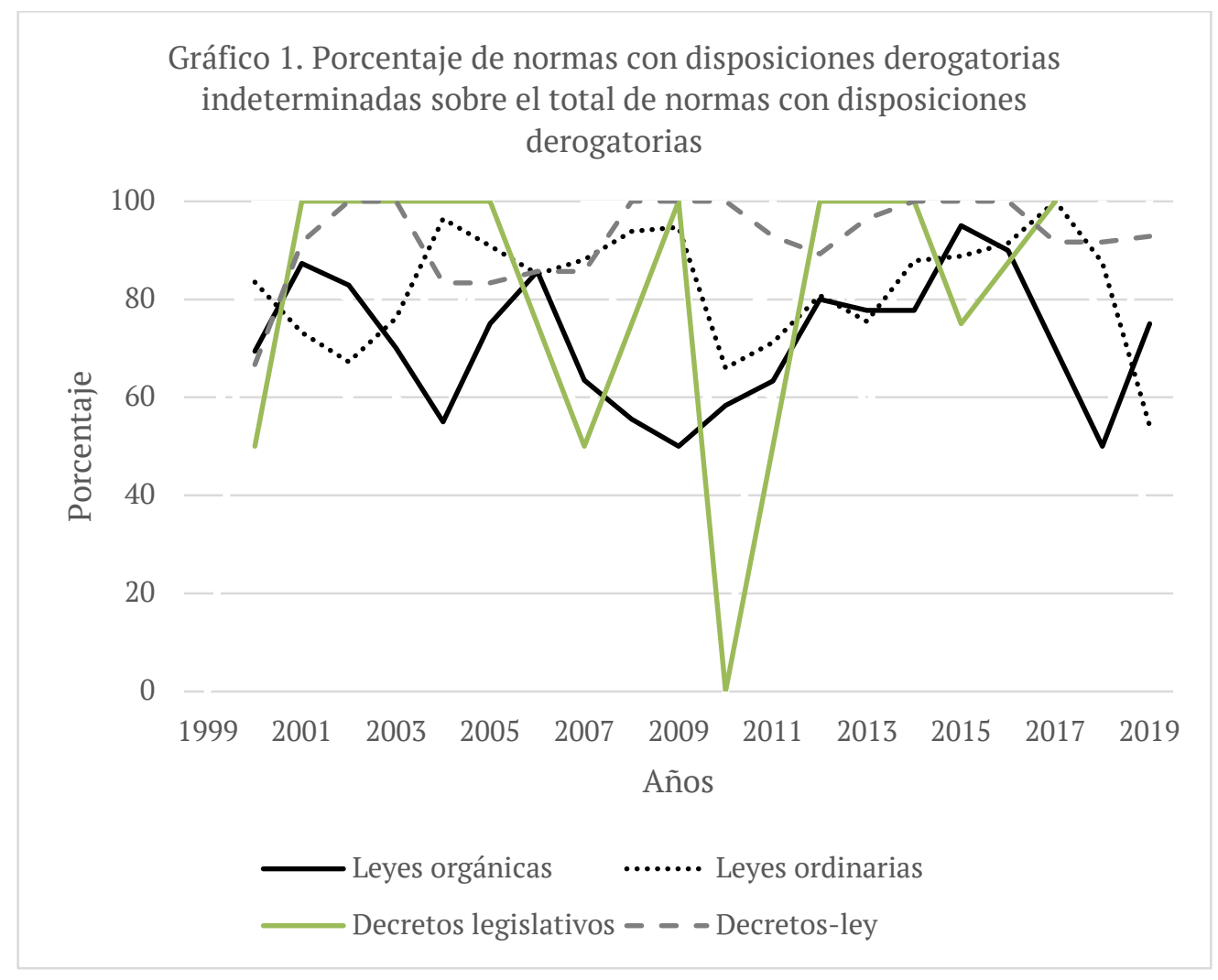

\footnotetext{
${ }^{29}$ En este sentido, se observa que en relación con numerosos de los dictámenes aquí citados (los núm. 88/2011, de 17 de febrero; núm. 1116/2015, de 10 de marzo de 2016; núm. 1439/2013, de 6 de marzo de 2014; núm. 99/2009, de 18 de marzo; núm. 1045/2001, de 9 de mayo y núm. 1361/1993, de 25 de noviembre), no se ha trasladado finalmente al texto normativo aprobado la rectificación propuesta por el Consejo en el sentido de prever cláusulas expresas de derogación.

${ }^{30}$ Para una cuantificación más específica y por tipología de norma de los resultados obtenidos, véase el anexo a este trabajo.
} 


\section{Fuente: elaboración propia a partir de los datos procedentes del BOE.}

De los datos analizados se deduce que la introducción de disposiciones derogatorias indeterminadas en nuestros principales tipos de normas es habitual (aparecen en un $71,59 \%$, $81,44 \%, 83,87 \%$ y en un $90,67 \%$ de las disposiciones derogatorias presentes en las leyes orgánicas, las leyes ordinarias, los decretos legislativos y los decretos-ley, respectivamente). Así, en más de aproximadamente tres cuartas partes de las normas que incluyen cláusulas derogatorias podemos encontrar cláusulas derogatorias indeterminadas. O, lo que es lo mismo, que sólo un 15-20\% de las normas que se aprueban en nuestro ordenamiento jurídico que contienen cláusulas derogatorias incluyen una relación específica, cerrada y determinada de las normas que dejan de ser aplicables una vez estas entran en vigor. Además, el uso de estas cláusulas, pese haber oscilado en el tiempo, se ha mantenido en términos absolutos en niveles altos de manera constante. En este aspecto, el fenómeno es particularmente grave en el caso de los Decretos legislativos para la elaboración de textos refundidos de diversas leyes, que suponen la práctica totalidad de los decretos legislativos aprobados analizados, en los que mayoritariamente, se utilizan este tipo de cláusulas (en un 76,47\% de las normas aprobadas encontramos cláusulas derogatorias indeterminadas) ${ }^{31}$. En estos casos en los que el objetivo de la norma aprobada tendría que ser la armonización, clarificación y expurgo de la legislación existente y la compilación en un solo texto de las distintas normas dispersas en el ordenamiento es especialmente preocupante el uso de este tipo de fórmulas derogatorias que denotan una evidente falta de análisis exhaustivo, completo y cuidadoso de la legislación existente en vez de la concreción expresa de todas las normas que hayan de quedar derogadas tras la aprobación de la nueva ${ }^{32}$.

Asimismo, de una observación de la tabla puede concluirse lo siguiente: 1) el uso de cláusulas derogatorias indeterminadas ha crecido en términos absolutos a lo largo de los 20 años analizados (aunque no de manera homogénea); 2), dicho uso no se ha visto reducido por la entrada en vigor de las Directrices de Técnica Normativa, aprobadas por Acuerdo de Consejo de Ministros de 22 de julio de 2005, que hacían especial hincapié en la necesidad de acabar con este tipo de cláusulas -aplicables íntegramente en la elaboración de los reales decretos legislativos y reales decretos-ley, que no muestran diferencias sustanciales en cuanto al uso de este tipo de cláusulas respecto de las leyes orgánicas y las ordinarias, en las que no serían de aplicación stricto sensu las Directrices-; y 3), el uso de estas disposiciones es mucho más acentuado cuando excluimos del análisis aquellas normas que no presentan ninguna disposición derogatoria, por lo que podemos afirmar que en más del 75\% de las disposiciones derogatorias de las normas aprobadas en el período analizado encontramos una cláusula de este tipo. Se confirma, por tanto, la falta de correlación entre las medidas adoptadas y las normas aprobadas, que de modo sistemático optan por esta forma de derogación.

\footnotetext{
31 De todos los Decretos legislativos aprobados en el período de referencia tan solo el Real Decreto Legislativo 1/1999, de 23 de diciembre, no es para la aprobación de un texto refundido.

32 Pese a todo, lo cierto es que en la totalidad de estos Decretos legislativos encontramos cláusulas mixtas (es decir, aquellas en las que, a pesar de introducirse la cláusula derogatoria indeterminada, sí se identifica[n] alguna[s] norma[s] a derogar de forma concreta), de lo que podríamos deducir que estas cláusulas genéricas aparecen con carácter complementario (como cláusula de cierre).
} 


\section{Los problemas de las disposiciones derogatorias indeterminadas}

\subsection{La afectación de los principios de seguridad jurídica y de publicidad de las normas}

La doctrina coincide en que una de las finalidades esenciales de la técnica legislativa es evitar la confusión normativa y la falta de cognoscibilidad del derecho por las personas que lo deben cumplir y aplicar. Esta finalidad está íntimamente relacionada con los principios de seguridad jurídica y de publicidad de las normas, reconocidos por la Constitución Española como dos de los más elementales de nuestro ordenamiento jurídico (art. 9.3) ${ }^{33}$.

La seguridad jurídica ha sido caracterizada por el Tribunal Constitucional como un principio compuesto por dos vertientes ${ }^{34}$. Una primera, de carácter más formal (u objetiva), que exige una formulación adecuada de las normas (clara y a través de un lenguaje accesible y sencillo) ${ }^{35}$. Y otra, de carácter material (o subjetivo), según la cual la seguridad jurídica se concretaría, "en la estabilidad del ordenamiento jurídico y, por tanto, en la confianza de los ciudadanos en que el contenido de aquel no va a ser modificado de forma arbitraria" ${ }^{36}$. Por tanto, el principio de seguridad jurídica conecta de un modo directo con la necesaria derogación expresa de las normas ${ }^{37}$. Así, tal y como indica la doctrina, la finalidad de las disposiciones derogatorias no es hacer posible el cambio de sistema jurídico, que tiene lugar al margen de que exista (o no) el instituto derogatorio, sino procurar "la ordenación necesaria para garantizar la cognoscibilidad y la certeza del derecho aplicable en cada momento" ${ }^{38}$. Son, en este sentido, un instrumento al servicio de la seguridad jurídica y de la confianza legítima de los ciudadanos ${ }^{39}$. Y, por tanto, la derogación indeterminada "plantea un problema de inseguridad jurídica, en el sentido de falta

33 Además de la doctrina ya referenciada, véase Pilar GARCíA-Escudero MÁrQuEz (2005), “Nociones de técnica legislativa para uso parlamentario”, Revista Parlamentaria de la Asamblea de Madrid, (13), págs. 121-164.

${ }^{34}$ Vidal Martín (2013).

${ }^{35}$ Sentencia 46/1990, de 15 de marzo, del TC (BOE núm. 85, de 9 de abril de 1990, ECLI ES:TC:1990:46).

36 VidAL MARTÍN (2013: 331).

37 Así, VidAl Martín (2013, p. 328), al que nos remitimos para un análisis más en profundidad de la jurisprudencia del TC en este aspecto, recuerda que el TC ha afirmado la conexión existente entre seguridad jurídica y derogación expresa en Sentencia 225/1998, al indicar que una determinada innovación normativa "se lleva a cabo, en lo que ahora importa, con certeza de la regla de Derecho, que se ha publicado formalmente y con expresa derogación de la normativa a la que sustituye [...]”, por lo que "no puede afirmarse que la caracterización del precepto recurrido como norma de Derecho transitorio conduzca en este caso, a una falta de certidumbre sobre el Derecho aplicable”.

${ }^{38}$ GASCÓn ABELLÁn (1994, p. 858).

${ }^{39}$ Pese a que el principio de protección de la confianza legítima no es un límite constitucional expreso al legislador (sí para la Administración, ex art. 3.1. e) de la Ley 40/2014, de 1 de octubre, de Régimen Jurídico del Sector Público), Andrés BoIX PAlop (2004), Las convalidaciones legislativas, Iustel Publicaciones, Madrid, pp. 287-288, subraya que "consideraciones materialmente coincidentes con lo que es la esencia de este principio en su versión administrativa han sido introducidas, y operan como límites a la actuación de todos los poderes públicos, a través de su integración en la figura de la seguridad jurídica”, como por ejemplo ha sucedido en la Sentencia 173/1996 del TC, de la que se deduce que en tanto en cuanto no haya un problema de confianza legítima, las normas podrán estimarse constitucionalmente aceptables. En este sentido, véase también Javier GARCíA LUENGO (2002), El principio de protección de la confianza en el Derecho administrativo, Civitas, Madrid. 
de certeza o de conocimiento claro de las normas vigentes, y, derivadamente, de desigualdad en la aplicación de la ley, pues si la valoración de la derogación de una norma se deja en manos de los operadores jurídicos, es muy posible que no todos ellos la estimen unánimemente derogada (o no derogada)" ${ }^{40}$.

Por su parte, el principio de publicidad de las normas, que puede entenderse comprendido en el de seguridad jurídica, implica no solo la cognoscibilidad de la publicación y el texto de las normas para que estas puedan producir efectos jurídicos, sino también el momento en que estas dejan de pertenecer de un modo activo al ordenamiento. En este sentido, la publicidad sobre el momento de cesación de la vigencia de la norma, debería alcanzar "el mismo grado de intensidad o general congnoscibilidad que ésta", algo que se alcanza de un modo cualitativamente distinto a través de la previsión general de publicidad de las sentencias ${ }^{41}$.

La consecuencia de la existencia de una norma que viole estos principios (como podría serlo una que no prevea de un modo claro y sencillo las derogaciones consecuencia de su adopción), es clara para el TC: esta se deberá declarar inconstitucional. Sin embargo, matiza a continuación nuestro más alto tribunal, solo en los casos en que las omisiones de una norma produzcan una confusión razonablemente insuperable podría concluirse que la norma infringe los principios de seguridad jurídica y publicidad de las normas ${ }^{42}$. Así, solo en casos de evidente e insuperable confusión (que no pudiera ser resuelta utilizando las reglas de interpretación admisibles en derecho desarrolladas por la jurisprudencia en estos casos y que describimos en el epígrafe quinto de este trabajo) podría ser enjuiciada la constitucionalidad de una cláusula derogatoria presente en una norma. Esto, en la gran mayoría de los casos, no sucederá, ya que este tipo de conflictos, que se manifiestan a la hora de la aplicación de las normas, es común que surjan y se resuelvan en una fase posterior a la de la inmediata publicación de la norma ${ }^{43}$.

\footnotetext{
${ }^{40}$ GASCÓN ABELLÁN (1994, p. 859), quien además puntualiza que “(f)rente a la rotundidad y seguridad que proporciona la derogación expresa -no sólo por establecer claramente qué disposiciones no podrán en adelante ser usadas para recabar normas jurídicas, sino también por la posibilidad de que se establezca un régimen de transitoriedad preciso- la llamada derogación tácita sitúa a los operadores jurídicos, y al mismo ciudadano, ante un desconcierto de normas que hace difícil saber cuál es en cada momento la regulación de una materia y que ciertamente nos aleja de aquél espíritu revolucionario de cognoscibilidad y previsibilidad del Derecho que inspirara la Codificación”. Es ilustrativo el ejemplo de AguiLó RegLA (1992, p. 275), quien indica que "(l)os sistemas automáticos de documentación de legislación son una buena muestra del distinto papel que juega el intérprete o aplicador del Derecho en uno y otro caso de derogación. Así, de acuerdo con lo aceptado, mientras que, cuando el legislador deroga expresamente, los responsables del sistema de documentación pueden realizar (y de hecho lo hacen) las operaciones de sustitución de unos textos por otros; en el caso de la derogación por incompatibilidad no pueden realizar operación alguna, pues se considera que su intervención resultaría siempre manipuladora, limitadora del papel del intérprete o aplicador del Derecho".

${ }^{41}$ Díez-Picazo Giménez (1990, p. 319).

${ }^{42}$ Véase Vidal Martín (2013), y jurisprudencia allí citada. En este sentido, indica Vidal Martín que, “[...] cuando un texto normativo no se plantea y resuelve por sí mismo de modo explícito todos los problemas que puede suscitar su aplicación, según el TC, estaremos en presencia de un ejemplo de empleo de una no depurada técnica jurídica en su proceso de elaboración pero ello no conllevará de manera inmediata la violación del principio de seguridad jurídica, siempre que la imprecisión de la norma recurrida y los problemas que la misma conlleva encuentren solución en el marco del ordenamiento vigente".

${ }^{43}$ En este sentido, es sintomático que hasta la fecha no haya analizado por el TC la inconstitucionalidad de ninguna cláusula derogatoria indeterminada en atención a su insuperable o imposible comprensión.
} 


\subsection{La controvertida naturaleza de los efectos de estas cláusulas}

Todo cuanto hemos indicado nos lleva a plantearnos las siguientes preguntas: ¿aporta algo incluir una cláusula de este tipo en una norma, o son estas disposiciones meras cláusulas de estilo cuya inclusión carece de todo valor normativo? ¿son realmente asimilables a la derogación expresa, o más bien a la tácita? En relación con esta cuestión, doctrina y jurisprudencia no se han manifestado de manera unánime.

Así, por un sector doctrinal se ha afirmado que estas cláusulas en general "no aportan nada y son redundantes en relación con el principio de lex posterior”, ya que en ambos casos se da una derogación de la norma en base a dicho principio ${ }^{44}$. Como consecuencia, ubica este tipo de cláusulas en la conocida como derogación tácita, tomando como carácter definitorio de la misma la remisión a la comprobación de la existencia de antinomias en sede de aplicación del derecho.

Por su parte, otro sector doctrinal, encabezado por DíEz-PiCAZo GiMÉNEZ, no admite una elaboración teórica "que concluye en la vaciedad normativa de toda una especie de disposiciones cotidianamente empleadas por el legislador”, ya que, con base en el argumento económico o hipótesis del legislador no redundante debe presumirse que todo cuanto dice la ley posee sentido ${ }^{45}$. En este sentido, indica que, en caso de aceptarse dicha argumentación, se presupondría la "identidad de naturaleza y efectos de la derogación expresa y la derogación tácita”. Y esta identidad, para el mismo autor, es ciertamente dudosa, ya que el criterio de diferenciación entre derogación expresa y tácita no es que en esta segunda exista una remisión a la comprobación de antinomias en sede de aplicación del derecho, sino que en la primera hay una disposición que claramente establece la consecuencia derogatoria mientras que en la segunda no la hay ${ }^{46}$. De este modo, lo que caracterizaría la derogación expresa, sería que en ella el efecto derogatorio "no procede del contraste entre normas, sino que se deriva directamente

\footnotetext{
${ }^{44}$ Josep Aguiló ReGLA (1992), “Derogación, rechazo y sistema jurídico”, Doxa, 11, págs. 263-280 (págs. 264268), quien subraya, además, que "sólo cabe considerar que media derogación cuando en la resolución del conflicto lo determinante es la ordenación temporal de las normas" y que, sin embargo, no hay derogación en la ordenación realizada con base en el principio de lex superior, "porque de su aplicación no se sigue nada parecido a la derogación, sino la declaración de nulidad de la norma inferior" ni al de lex especialis, ya que este principio, básicamente, "opera como un criterio de individualización de disposiciones jurídicas". En definitiva, indica que "solo la ordenación en base al criterio de lex posterior puede ser equiparada a la derogación expresa realizada por el legislador, pues solo ella produce efectos semejantes a los de esta” (1992, p. 274). En ese sentido, véanse también Ricardo GuARINONI (2006), “Derogación y después”, Isonomía - Revista de teoría y filosofía del derecho, 24, págs. 77-91; y VIDAL MARTín (2013).

${ }^{45}$ Díez-Picazo Giménez (1990, p.153).

${ }^{46} \mathrm{Ibid}$, p. 154. Por tanto, según este razonamiento la mera existencia de una antinomia no ha de implicar, necesariamente y en todo caso, la pérdida de vigencia de la más antigua de las normas incompatibles, sino simplemente que, con base en el criterio de prevalencia de por la lex posterior, se entienda que su eficacia ha quedado suspendida. De este modo, tampoco puede derivarse, en ningún caso, la invalidez ni, menos aún, cesación de vigencia de la norma anterior en el tiempo y, como consecuencia, los efectos de este tipo de derogación serían reversibles: en caso de desaparecer el motivo de la suspensión de la eficacia, la ley reviviría y readquiriría toda su capacidad reguladora, ya que continuaría perteneciendo al ordenamiento (Ibid, p. 331 y ss.).
} 
de la disposición derogatoria” y por tanto en ella quedarían comprendidas también las disposiciones derogatorias indeterminadas, que conceden ese efecto derogatorio a la incompatibilidad; mientras que en la tácita, al no haber una norma sobre la producción jurídica de la que se pueda derivar el efecto derogatorio, no podría entenderse que este ocurre ${ }^{47}$.

Para poder afirmar que no hay norma alguna que otorgue efecto derogatorio a la incompatibilidad se realiza un verdadero esfuerzo hermenéutico dirigido a enervar lo previsto por el art. 2.2. CC, que es el artículo en el que tradicionalmente se ha basado el poder derogatorio de la norma posterior incompatible con la anterior (en el que, como el mismo autor reconoce, la voluntas legis consistente en otorgar identidad de efectos a ambos tipos de derogación es inequívoca). En este sentido, se argumenta que esta norma tiene el inconveniente de que "oculta, o al menos, deja en la penumbra las marcadas diferencias estructurales que median entre la derogación expresa y la derogación por incompatibilidad (esto es, la derogación tácita), ya que no atribuye relevancia alguna en sede de efecto derogatorio a dos circunstancias propias de esta última, a saber: la indeterminación del objeto derogatorio y las consiguientes operaciones que han de desarrollar los órganos de aplicación del Derecho a fin de delimitar aquél” ${ }^{48}$. La concurrencia de estas circunstancias, contrarias al principio de seguridad jurídica, al de publicidad de las normas y a los límites constitucionales a la potestad jurisdiccional le llevan a encontrar lo prescrito por el art. 2.2 CC irreconciliable con las previsiones constitucionales y a afirmar que no procede, en cualquier caso, configurar la derogación por incompatibilidad de modo que se atribuya a esta un efecto derogatorio en sentido propio (de cesación definitiva de la vigencia de la ley).

Sin embargo, esta postura parece olvidar que, según su propia definición, la misma derogación expresa también comprendería un fenómeno que presenta problemas muy similares (por no decir, idénticos) a los que presenta la derogación tácita (y en los cuales, precisamente, se justifican sus diferencias respecto de la derogación expresa y su falta de poder derogatorio): las disposiciones derogatorias indeterminadas. La inclusión de estas cláusulas (que presentan problemas equivalentes en cuanto a la falta de seguridad jurídica y de publicidad de las normas y al traspaso del poder de decisión sobre la vigencia de las normas a los operadores jurídicos, como hemos visto) dentro del fenómeno de la derogación expresa supone incurrir en una contradicción difícil de salvar: o bien se reconoce a toda derogación indeterminada (sea expresa o tácita) similar poder derogatorio y se acepta la vigencia del art. 2.2 CC, o bien se inaplica, por inconstitucional, tanto dicho artículo del Código Civil como las normas que prevén cláusulas

\footnotetext{
${ }^{47}$ En sus propias palabras: "en la derogación por incompatibilidad [la subcategoría más importante en que se divide la derogación tácita, la otra sería la derogación por nueva regulación integral de la materia], bien hay una norma de carácter general -distinta, pues, de las normas ad hoc propias de las disposiciones derogatorias- que establezca la cesación de la vigencia y, por consiguiente, derogación expresa y derogación por incompatibilidad son dos fenómenos cualitativamente distintos. Este es el dilema dogmático que suscita la derogación por incompatibilidad en cuanto a sus efectos" (Ibid, p. 316).

${ }^{48}$ Ibid, p. 333, concluye así que "no se puede olvidar que el art. 2.2 CC, norma de rango legal, sólo puede tener fuerza vinculante general en la medida en que se adecue a los dictados constitucionales. [...]. La interpretación constitucional del sistema de fuentes, en el que está incluida la llamada derogación por incompatibilidad, no puede plegarse ante las anticuadas previsiones del Código en esta materia. El art. 2.2 CC debe ser interpretado de conformidad con la Constitución y no viceversa".
} 
derogatorias indeterminadas $-\mathrm{y}$, como mínimo, se entiende que tanto las disposiciones indeterminadas como la derogación tácita carecen de cualquier fuerza derogatoria-. Y esto porque los argumentos utilizados para diferenciar ambas clases de derogación y para quitarle valor derogatorio al fenómeno de la derogación tácita pueden trasladarse a esta subcategoría de derogación expresa.

En cierta forma, se intenta solucionar este problema a través de la división de las cláusulas derogatorias indeterminadas en dos clases, las absolutamente genéricas, que "no pueden ser reconducidas al esquema de la derogación expresa -y hay que concluir, por tanto, que son efectivamente inútiles-" (y se asimilan, por consiguiente, a la derogación tácita) y las que, indicando un texto "condicionan el efecto derogatorio a la constatación en sede interpretativa de que existe una antinomia”, que sí deberían ser entendidas auténticos actos de derogación ${ }^{49}$. Esta distinción, sin embargo, nos resulta artificiosa, ya que revela cierta falta de sistematicidad a la hora de atribuir consecuencias muy relevantes a las normas en cuestión. En especial, no llegamos a entender la justificación subyacente con base en la cual, en caso de que no se identificase en la disposición derogatoria el concreto texto legal respecto del que podría existir una incompatibilidad, se inactivase (por decirlo de algún modo) el poder derogatorio de dicha disposición. Y, por este mismo motivo, nos resistimos a aceptar algunas de las consecuencias del planteamiento descrito, especialmente la regla de la reviviscencia de las normas, que hace un flaco favor al principio de seguridad jurídica y produce efectos muy diferentes para situaciones que a nuestro parecer son sustancialmente idénticas.

Esta cuestión no ha sido tampoco resuelta de forma definitiva por nuestros tribunales, pese a que hasta la fecha sí que han identificado las derogaciones indeterminadas dentro de la categoría de la derogación tácita (a la que han dado, además, un auténtico poder derogatorio y no de mera suspensión o inaplicación transitoria). En este sentido encontramos una serie de sentencias de especial interés dictadas recientemente por el Tribunal Superior de Justicia de Madrid y el Tribunal Supremo, en las que se analiza -casi como si ante un caso de laboratorio nos encontrásemos- esta situación. En ellas se discute la posible derogación tácita de una ley especial por parte de una ley de carácter general posterior en el tiempo, así como la posible reviviscencia de las previsiones de esta primera ley especial tras la derogación expresa posterior de la ley de carácter general que la derogaba tácitamente. Asimismo, de su análisis se deduce una división de criterio sustancial entre la Sección Segunda y la Séptima del TSJ de Madrid, que analizan casos idénticos: mientras que la primera, sin cuestionar una sentencia previa del Tribunal Supremo que declaraba derogada tácitamente dicha ley especial, confirma dicha derogación tácita así como la no reviviscencia de la norma especial tras la derogación expresa de la norma que la derogaba tácitamente ${ }^{50}$; la segunda se atreve a apartarse del criterio de la Sentencia del Tribunal Supremo que apreciaba dicha derogación tácita (por entender que una ley general posterior no puede derogar de forma tácita una ley especial anterior) y afirma la reversibilidad de los efectos de la derogación tácita una vez desaparecida la antinomia

\footnotetext{
${ }^{49}$ Ibid, p. 156.

${ }^{50}$ Sentencias 723/2017, de 31 de octubre (recurso núm. 20/2016, ECLI: ES:TSJM:2017:11297) y 727/2017, de 31 de octubre (recurso núm. 436/2016, ECLI: ES:TSJM:2017:11365).
} 
normativa ${ }^{51}$. Así, las distintas concepciones sobre el fenómeno de la derogación representadas reflejan a la perfección el conflicto descrito hasta ahora, y por ello son especialmente interesantes las sentencias dictadas en casación de estas por parte del Tribunal Supremo. Y, de momento, parece que este se inclina por otorgar idénticos efectos a la derogación expresa y la tácita, ya que en ambas casaciones de las resoluciones de la Sección Segunda del TSJ de Madrid, el Tribunal Supremo ha confirmado el planteamiento de esta Sección ${ }^{52}$, aunque el recurso contra la de la Sección Séptima (que fue dictada antes de la publicación de las sentencias del Tribunal Supremo), se encuentra todavía pendiente, después de haber sido admitido en atención a su especial interés casacional.

A pesar de que el conflicto relatado no lo es en relación con cláusulas derogatorias indeterminadas, su resolución sí que afecta de un modo directo a los efectos previsibles que la inclusión de este tipo de cláusulas causa. Así, de confirmarse como creemos que sucederá por el Tribunal Supremo que en caso de derogación tácita no hay reviviscencia de la norma anterior si posteriormente se deroga expresamente la que la derogaba (que es la tesis que aquí mantenemos), desaparecerá la única diferencia que podría aducirse entre la derogación tácita y las cláusulas derogatorias indeterminadas. Asimismo, se corroborará que estas últimas son cláusulas totalmente prescindibles que se usan de modo sistemático por el bajo coste que tienen para el legislador en comparación a estudiar y analizar concienzudamente el ordenamiento jurídico vigente y determinar de un modo más específico la normativa a derogar ${ }^{53}$. Y, finalmente, también perderá fuerza el argumento -utilizado a veces para justificar el uso extensivo e indiscriminado de estas cláusulas en toda clase de normas-, de que, en caso

\footnotetext{
${ }^{51}$ Sentencia 419/2019, de 23 de mayo, recurso núm. 873/2018, ECLI: ES:TSJM:2019:4092. Por lo relevante de su argumentación, trasladamos aquí alguno de sus pasajes, en el que se indica que, "la derogación tácita es más bien una regla de aplicación, para solventar antinomias o conflictos normativos, y que, como de todos es sabido, suele plantear serios problemas de interpretación y aplicación por su especial complejidad. El criterio de la lex posterior, que es el utilizado en la STS 27/12/2013 , para resolver un problema de incompatibilidad normativa que advierte entre la LCREM y el EBEP, suele operar como una simple regla o técnica de aplicación del derecho por el intérprete, de modo que deja inaplicada la norma anterior, pero, a diferencia de lo que ocurre con la derogación expresa, la norma anterior permanece en el ordenamiento, pudiendo entonces ser rediviva; de esta forma los efectos de la "derogación tácita" son reversibles, una vez desaparecida la antinomia, puesto que no vincula al legislador; la inaplicación de una norma por considerarla derogada tácitamente no es equiparable a su expulsión total del ordenamiento, lo que, como decimos, no tiene lugar mientras no sea derogada por otra ley. Esto nos los muestra el propio auto mencionado del Tribunal Supremo admitiendo el recurso de casación 655/2018, al plantear, no solo si el artículo 55 de la LCREM fue derogado tácitamente por lo dispuesto en la disposición adicional segunda del EBEP, si no también, si ha recobrado (o no) su vigencia como consecuencia del artículo 92 bis de la LRBRL. La reversibilidad sería impensable en los supuestos de derogación expresa, noción a que, a todo esto, debe entenderse referido el art. 2 CC, y a su prohibición de que por la simple derogación de una ley recobran vigencia las que ésta hubiere derogado".

52 Sentencias de la Sección Cuarta del TS 863/2020, de 23 de junio (recurso núm. 655/2017, ECLI ES:TS:2020:1804) y 869/2020, de 24 de junio (recurso núm. 730/2018, ECLI ES:TS:2020:2033).

${ }^{53}$ En este aspecto, coincidimos con Louis KaPLow (1992), "Rules versus Standards: an Economic Analysis”, Duke Law Journal, 42, págs. 557-629, quien sospecha que en determinadas ocasiones el recurso a los standards (normas que, como veremos en el siguiente epígrafe, son relativamente asimilables a estas cláusulas por dejar a la fase de aplicación de las normas la especificación de determinados aspectos del supuesto de hecho de estas), más que por una razón de fondo viene justificado por las presiones temporales y de calendario, el deseo de transferir los costes de concretar la norma a los aplicadores de derecho o por simples errores en el procedimiento de elaboración de la norma.
} 
de que el legislador se olvide de incluir alguna norma en el listado de normas derogadas expresamente, su carencia provoque consecuencias no queridas (como podría serlo que se apreciase la suspensión de la eficacia de una norma en vez de su pérdida de vigencia). Y esto porque, en cualquier caso, se deberá interpretar que en caso de incompatibilidad insalvable se ha producido una derogación tácita de la norma anterior y, por tanto, dará igual que esta cláusula general de salvaguardia esté o no presente ${ }^{54}$.

\subsection{La realidad alternativa}

¿Qué sucedería si, en cambio, el Tribunal Supremo negase poder auténticamente derogatorio a la derogación tácita? ${ }^{55}$ Pues bien, además de generarse un auténtico seísmo jurídico -para el que no sabemos si nuestro ordenamiento jurídico está preparado-, en este caso entendemos que, de paso, entraría en juego la posibilidad de considerar, en este aspecto, las tesis del legislador racional (según las cuales las personas encargadas de la redacción normativa cuidan cada palabra que aparece en la ley). Y esto porque solo en ese caso el recurso constante a estas cláusulas se podría entender que ha respondido y responde a una decisión racional, consciente y fundamentada en un análisis de los costes asociados a la tarea legislativa.

Así, de confirmarse que, de hecho, vivimos en esta realidad alternativa en la que unas normas pueden revivir cuales "zombis" normativos y recobrar su vigencia tras la derogación de la norma que tácitamente las derogaba, recurrir a estas cláusulas podría ser justificable, y bajo ciertos condicionamientos, con la finalidad de evitar que determinadas normas resuciten. $\mathrm{Y}$ esto porque (1), la identificación total de las potenciales normas que van a entrar en conflicto con la nueva y que tienen que declararse derogadas puede ser una tarea compleja y que requiere de una inversión de recursos muy elevada y (2), en este caso entendemos que la relevancia de las consecuencias jurídicas podría justificar los efectos negativos inherentes a la introducción de este tipo de normas. Sería así, en estos concretos casos, en que entenderíamos aceptable el recurso (limitado) a normas de este tipo que dejasen a una fase posterior de la aprobación de este determinar qué otras normas efectivamente entran en contradicción con él.

En este sentido, la literatura estadounidense ${ }^{56}$ ha identificado aquellas normas que predeterminan con gran precisión el supuesto de hecho al que se asocia una determinada consecuencia jurídica, conocidas como rules (y de las que podría ser un ejemplo un precepto del tipo "está prohibido arrojar mercurio y plomo a las aguas superficiales") y aquellas cuyo contenido está configurado con una elevada abstracción, y que por tanto, necesita ser concretado posteriormente y a la vista de las circunstancias específicas del caso para que se pueda determinar cuál es la consecuencia jurídica asociada a este, conocidas como standards

\footnotetext{
${ }^{54}$ Sobre este argumento volveremos en el epígrafe 5.1 de este trabajo, con ocasión del análisis del principio interpretativo de conservación de las normas.

${ }^{55} \mathrm{O}$ también si nos encontráramos ante un sistema jurídico que, a diferencia del nuestro, no tiene una regla asimilable al art. 2.2. CC.

56 Véanse, en este sentido, Kaplow (1990), Russell B. Korobкin (2000), “Behavioral Analysis and Legal Form: Rules vs. Standards Revisited”, Oregon Law Review, 79 (1), págs. 23-60; y Ezra FrIEDMAN y Abraham L. Wickelgren, “A New Angle on Rules versus Standards”, American Law and Economics Review, págs. 499549.
} 
(por ejemplo, "está prohibido arrojar sustancias químicas inorgánicas contaminantes a las aguas superficiales"). Con carácter general, se prefiere el uso de rules sobre el de standards. Y es que, a favor de las rules se argumenta que garantizan (1) una mayor seguridad jurídica (y por tanto también, la reducción en los errores en que se incurre sobre el derecho aplicable); (2) un abaratamiento de los costes de aplicación del derecho (los costes de información sobre el contenido de las normas, el tiempo en solucionar el conflicto y el número de conflictos que surgirán serán presumiblemente menores); (3) un incremento en el grado de cumplimiento de las normas y, (4) límites a la discreción y, por tanto, abusos de poder, por parte de los poderes públicos. ${ }^{57}$ Por su parte, a favor del uso de standards encontramos (1), la reducción de costes en el momento de promulgar las normas (requieren un análisis menos en profundidad en el momento de diseño de las normas) y (2) los beneficios que pueda acarrear la mejor identificación de los criterios de concreción del margen de indeterminación dejado por la norma por parte de una Administración que esté mejor posicionada, por disponer de estructuras organizativas y procedimentales más idóneas para la elaboración de esos criterios, que el legislador, para resolver estos conflictos. Estas razones, además, son especialmente relevantes en relación con materias cuya casuística es compleja y variable o que están sujetas a innovaciones científicas y/o tecnológicas.

Esta distinción, que, a grandes rasgos, podría ser trasladable al debate de la determinación o no de las cláusulas derogatorias ${ }^{58}$ busca, en definitiva, maximizar los beneficios netos de los costes de las normas, que dependen básicamente de las diferencias en los costes en su promulgación (que favorecen los standards) y en aplicación (que favorecen las rules). Así, podríamos aceptar que en esta realidad alternativa (fuera de ella, en este aspecto, más que a un legislador inteligente encontramos a uno perezoso) se justifique el uso de disposiciones derogatorias indeterminadas. En este caso, además de apostar por una doctrina del precedente más sólida y sistemática, sería necesario que se circunscribiera el uso de estas cláusulas a determinados supuestos complejos en los que los costes de identificar las potenciales incompatibilidades normativas sean muy altos y las posibilidades de aplicación muy reducidas.

\subsection{Su interpretación: ¿cuándo se entiende derogada una norma no derogada expresamente?}

\footnotetext{
${ }^{57}$ En este sentido, además, los estudios en economía del comportamiento y teoría de la elección racional (KorobKIN, 2000), indican que tanto el sesgo por interés personal (self-serving bias) como el sesgo de retrospectiva (hindsight bias), son menos problemáticos y, por tanto, hay menos probabilidad de que se den, en un sistema regido por rules frente a uno regido por standards.

${ }^{58}$ Encontramos barreras a la hora de aplicar la teoría de los rules y los standards al fenómeno que nos ocupa. Así, en primer lugar, no nos hallamos ante una necesidad de adaptar al caso concreto las normas, que es la base del sistema de los standards (puesto que las normas o están derogadas o no lo están en atención a una incompatibilidad que nada tiene que ver y es totalmente independiente del conflicto fáctico subyacente), sino de concretar en ese caso el contenido de la derogación-. De similar forma, no es aplicable el pretexto que se da a veces para defender la introducción de standards, cual es que en casos de innovaciones o de cambios en las circunstancias, estos se adaptan mejor, puesto que en relación a las cláusulas derogatorias no se pueden dar esta clase de situaciones. Por otro lado, tampoco favorece a la implantación de este régimen el deficiente desarrollo de la doctrina del precedente en nuestro país y que el hecho de que, en cualquier caso, para conseguir llegar a generar ese precedente hay que recorrer aquí un largo camino que por lo general suele alargarse durante muchos años e instancias.
} 
Finalmente, analizados los problemas de la derogación indeterminada desde el punto de vista de la técnica legislativa, se impone la necesidad de analizar el modo en que nuestros tribunales resuelven los conflictos que se dan respecto de la interpretación de este tipo de cláusulas. Como indicábamos, el art. 2.2 CC establece que la "derogación tendrá el alcance que expresamente se disponga y se extenderá siempre a todo aquello que, en la ley nueva, sobre la misma materia sea incompatible con la anterior”. Así, en los casos en que nos encontremos ante derogaciones indeterminadas, habrá que estar a la concreta identificación de dicha incompatibilidad para determinar la vigencia o no del texto normativo concreto. En la realización de esta actividad hermenéutica han sido jurisprudencia y doctrina las que han sentado las bases para solucionar las cuestiones que en aquellos casos más complejos se han ido planteando y han asentado una serie de elementos a tener en cuenta: que la derogación no puede presumirse, que deben cumplirse una serie de requisitos para entender que concurre dicha contradicción y cómo deben resolverse los conflictos que surgen cuando los principios de jerarquía, temporalidad y especialidad entran en conflicto entre ellos ${ }^{59}$.

\section{a. La no presunción de la derogación}

Múltiples pronunciamientos de nuestros tribunales ${ }^{60}$, así como la doctrina ${ }^{61}$, han destacado que la derogación no puede presumirse, en atención al carácter normativo de las leyes y los reglamentos y a los principios constitucionales de publicidad y seguridad jurídica. A favor de este principio general de conservación de las normas se ha pronunciado el Tribunal Supremo en Sentencia 573/2010 de 30 de septiembre, en la que ha indicado que rige "en nuestro sistema un principio de coherencia, imperativo no sólo para el legislador, sino también para el intérprete, al que le impone buscar, primero, la compatibilidad lógica entre la norma moderna y la antigua, para superar, con los medios técnicos a su servicio, las antinomias y contradicciones posibles regla de conservación -. Y sólo en defecto de esa posibilidad, dar entrada al instituto de la derogación tácita, cual instrumento necesario finalmente para salvar la cohesión de todo el sistema mediante la afirmación, en el caso, del cese de la vigencia de una de las leyes en conflicto" ${ }^{2}$.

\footnotetext{
${ }^{59}$ Entre ellos, destacamos aquellos más íntimamente relacionados con la derogación indeterminada y dejamos de lado aquellos que pueden aflorar en relación con el fenómeno derogatorio en general (como puede ser, por ejemplo, el análisis de los efectos de la derogación sobre las situaciones nacidas al amparo de la normativa anterior, que no cambiaría en el caso de encontrarnos ante una derogación determinada o una indeterminada).

${ }^{60}$ Por todas, Sentencia 5789/2010 de la Sala de lo Civil del TS, de 29 de septiembre de 2010 (recurso núm. 683/2007, ECLI ES:TS:2010:5789), que indica que "lo anteriormente expuesto es la consecuencia de que rija en nuestro sistema un principio de coherencia, imperativo no sólo para el legislador, sino también para el intérprete, al que impone buscar, primero, la compatibilidad lógica entre la norma moderna y la antigua, a fin de superar, con los medios técnicos a su servicio, las antinomias y contradicciones posibles regla de conservación -. Y sólo en defecto de esa posibilidad, dar entrada al instituto de la derogación tácita, cual instrumento finalmente necesario para salvar la cohesión de todo el sistema mediante la afirmación, en el caso, del cese de la vigencia de una de las leyes en conflicto".

${ }^{61}$ Díez-Picazo Giménez (1990) y Vidal Martín (2013).

${ }^{62}$ Recurso núm. 670/2007, ECLI ES:TS:2010:5027.
} 
Como consecuencia de este principio de conservación de las normas, se ha entendido que el que una norma posterior en el tiempo (salvo aquella que venga a introducir una nueva regulación integral de la materia) no incluya determinados preceptos contenidos en la anterior no puede ser considerado como una contradicción normativa, por lo que de darse una derogación indeterminada solo lo será respecto de aquellos preceptos con los que de modo efectivo la nueva norma entre en contradicción ${ }^{63}$. Así, en caso de conflicto entre diferentes preceptos normativos, siempre hay que tratar de integrar ambas normas (la presuntamente derogada y la nueva) y, en caso de poder encontrar alguna interpretación que concilie la existencia de ambas, no entender derogada tácitamente norma alguna.

Asimismo, en relación con este aspecto, es relevante analizar el valor interpretativo que se le da a la existencia de una cláusula derogatoria determinada respecto de las disposiciones que, bien de un modo indeterminado o bien de un modo puramente tácito, se derogan: ¿implica el principio de conservación de las normas que, al no haber sido nombradas expresamente, estas se tienen que tener en todo caso por no derogadas? ¿hay diferencias entre aquellos casos en que se incluye, además de la cláusula de derogación determinada, una cláusula derogatoria indeterminada de cierre de aquellos en que no? Al respecto, nuestra jurisprudencia ha entendido de un modo pacífico que, en caso de encontrarnos ante la existencia de una cláusula derogatoria determinada y dudar sobre la posible derogación de otras normas no enumeradas en dicha disposición, rige también el principio de conservación de las normas, pero que este no impide que, por no haber sido nombradas expresamente, estas normas no se puedan entender derogadas tácitamente. Esto es, que las cláusulas derogatorias expresas no son, con carácter general y salvo que prevean lo contrario de un modo explícito, una enumeración numerus clausus de las normas que pierden su vigencia. Por este motivo, conjuntamente con el reconocimiento de poder derogatorio pleno a la derogación tácita, no parece necesario que, con la finalidad de despejar cualquier duda, se introduzca, en cualquier caso, una disposición derogatoria indeterminada de cierre. Y, por tanto, el único efecto que entendemos que puede tener la inclusión de estas cláusulas en las normas es el de repetir o recordar el derecho ya vigente.

En estos casos en que encontramos una derogación expresa de determinadas normas, lo que sí que ha indicado ANDRONIO ${ }^{64}$ al estudiar el fenómeno es que las normas que la cláusula derogatoria identifica sí que pueden servir como criterio interpretativo a la hora de enfrentarse a normas que potencialmente se han derogado de un modo indeterminado o tácito. Es decir, que si en la cláusula derogatoria se incluye expresamente alguna norma que sí se deroga, puede que del análisis de los motivos por los que se ha previsto la derogación expresa de esa norma se derive algún criterio para la interpretación de las normas potencialmente derogadas tácitamente. Pero, de cualquier forma, el valor interpretativo que se le pueda conceder a la enumeración realizada en la cláusula derogatoria no empece para afirmar que la omisión de

\footnotetext{
${ }^{63}$ En este sentido, Sentencias de la Sala de lo Contencioso del TSJ de la Comunidad Valenciana, de 25 de mayo de 2007 (recurso núm. 392/2007, ECLI ES:TSJCV:2007:2310), y de 2 de mayo de 2018 (recurso núm. 98/2016, ECLI ES:TSICV:2018:2017). Asimismo, sobre la derogación por regulación integral de la materia véase DíEZ-PicAZo GiménEZ (1990).

${ }^{64}$ ANDRONIO (1997).
} 
una norma concreta signifique, en cualquier caso, una decisión consciente del legislador por la que declara no derogada aquella norma. Esta conclusión refuerza el argumento indicado anteriormente en relación con la innecesaridad del uso de cláusulas derogatorias indeterminadas de forma preventiva ( $y$, en la actualidad, extensiva e indiscriminada) para el caso de que el legislador se olvide de incluir alguna norma en el listado de normas derogadas expresamente (cuyo uso, consideramos, contribuye en muchos casos a que el legislador no se esfuerce por identificar las normas que van a dejar de estar en vigor tras la nueva normativa).

Finalmente, cabe hacer un último apunte relacionado con la posibilidad de que una norma se derogue en varias ocasiones por distintas normas promulgadas en diferentes momentos temporales, primero de forma tácita y, después, de forma expresa. En este caso, el principio de presunción de no derogación que hemos explicado no implicaría, evidentemente, que la derogación expresa de una norma supusiera que esta no pudiera haber sido anteriormente derogada de forma tácita. Es decir, una derogación tácita no deja de surtir efectos porque más tarde otra norma la convierta en expresa, que solo tiene el efecto de confirmar o insistir en esta derogación (y dar, a su vez, una mayor seguridad jurídica). Lo decisivo no es lo que la norma posterior diga, sino si la disposición de cuya vigencia se trata quedó o no afectada antes por la regulación material de otra norma de la misma o superior jerarquía ${ }^{65}$.

\section{b. Los requisitos de incompatibilidad}

A la hora de entender derogada implícitamente una norma existen tres requisitos fundamentales relacionados con la incompatibilidad entre la nueva norma y la preexistente: (1) la igualdad de materia en ambas, (2) la identidad de destinatarios, y (3), la contradicción e incompatibilidad entre sus fines. Estos requisitos, reflejados por la máxima ya anunciada por la Sala de lo Contencioso del Tribunal Supremo en Sentencia de 4 de noviembre de 1992 -esto es, que nos encontremos ante una contradicción clara y tajante entre la norma que deroga de forma tácita una norma y la anterior- ${ }^{66}$; fueron establecidos por una serie de Sentencias del Tribunal Supremo de los años noventa ${ }^{67}$ y posteriormente confirmados por el Tribunal

\footnotetext{
${ }^{65}$ En este sentido, sentencias de la Sala de lo Contencioso del TS de 9 de marzo de 1995 (recurso núm. 2331/1992, ECLI ES:TS:1995:1380) y de 12 de julio de 2000 (recurso núm. 2578/1993, ECLI ES:TS:2000:5788).

${ }^{66}$ ECLI ES:TS:1992:18708.

${ }^{67}$ Entre estas podemos destacar la Sentencia del TS, Sala de lo Penal, de 21 de octubre de 1991 (ECLI ES:TS:1991:7964), la de la Sala de lo Civil, de 31 de octubre de 1996 (recurso núm. 46/1993, ECLI ES:TS:1996:5990); la de la Sala de lo Contencioso, de 26 de marzo de 1998 (recurso núm. 7003/1993, ECLI ES:TS:1998:2022). Entre ellas, la de 26 de marzo de 1998 es especialmente ilustrativa al indicar que “(e)n el caso de la derogación expresa, no hay dificultad para aplicar la regla esencial del Derecho, consistente en que la ley posterior deroga la ley anterior, pero cuando la ley no contiene una cláusula derogatoria explícita, nace la cuestión de averiguar qué disposiciones quedan derogadas en cada caso y es evidente que cuando hay una contradicción insuperable con las leyes anteriores, la derogación se puede presumir, pero en todo caso se impone una importante tarea interpretativa que han de llevar a cabo los Tribunales para determinar el alcance y contenido de la derogación, puesto que es clásico en el sistema jurídico y en la teoría general del Derecho el reconocimiento de que para que se admita la derogación de la nueva disposición respecto de la anterior, han de cumplirse una serie de presupuestos cuales son: a) La igualdad en la materia de ambas leyes, b) la identidad de los destinatarios de los mandatos legales y c) La contradicción e incompatibilidad entre los fines de los referidos preceptos”.
} 
Constitucional, que ha indicado que no cabe la derogación tácita de una ley en virtud de otra posterior cuando la materia de ambas es distinta y diferente la perspectiva de la regulación ${ }^{68}$. $\mathrm{O}$, en otras palabras, que resulte "lógicamente imposible aplicar una norma sin violar otra, para lo cual debe llevarse a cabo una labor interpretativa que exige una actividad hermenéutica, más o menos compleja, de esclarecimiento del significado del antiguo y del nuevo texto legal” ${ }^{\circ}$. De similar manera, la doctrina ha propuesto definir la contradicción en términos del cumplimiento de la norma: dos normas son contradictorias cuando el cumplimiento de una de ellas excluye, por razones lógicas, el cumplimiento de la otra ${ }^{70}$.

Para el análisis sobre la concurrencia de estos requisitos serán de aplicación las normas generales de interpretación contenidas en el artículo 3.1. CC (interpretación según el sentido propio de las palabras, su contexto, los antecedentes históricos y legislativos, la realidad social del tiempo en que han de ser aplicadas y el espíritu y finalidad de estas). Así, la Sentencia del Tribunal Superior de Justicia de Madrid de 13 de mayo de $2016^{71}$ ha indicado que "las dificultades y problemas que en este ámbito se planteen deben resolverse examinando la finalidad o intención legislativa, los principios que la inspiraron, el posible enfrentamiento de las disposiciones en conflicto y la amplitud reguladora material de la Ley posterior, si es total o parcial, para conocer si quiso o no liquidar el sistema precedente o si es posible, en fin, la concurrencia de las normas en supuesta contradicción y no se excluyen o repelen”. Sin embargo, en casos de conflicto sobre la derogación o no de una norma, el Tribunal Supremo ha destacado el criterio de interpretación según el contexto de la norma (el sistema normativo al que pertenece), sobre el del estudio de los antecedentes históricos o legislativos ${ }^{72}$. Asimismo, se ha apreciado que en caso de duda sobre la existencia de contradicción normativa también se deberá estar al principio pro libertatis, esto es, se deberá entender que prevalece aquella interpretación que sea más favorable a la libertad de mercado ${ }^{73}$.

\footnotetext{
${ }^{68}$ Sentencia 102/1995, de 26 de junio (ECLI ES:TC:1995:102).

${ }^{69}$ Sentencia de la Sala de lo Contencioso del TSJ de Andalucía de 5 de febrero de 2010 (recurso núm. 551/2007, ECLI ES:TSJAND:2010:1700).

70 Carlos E. Alchourrón y Eugenio Bulygin (1991), Análisis lógico y Derecho, Centro de Estudios Constitucionales, Madrid, p. 407, y Aguiló Regla (1992).

${ }^{71}$ Recurso núm. 347/2015, ECLI ES:TSJM:2016:3241.

${ }^{72}$ Así, en Sentencias 5789/2010, de 29 de septiembre y 564/2010, de 30 de septiembre (recurso núm. 670/2007, ECLI ES:TS:2010:5027), la Sala de lo Civil del TS ha afirmado que "(e)n esa labor hermenéutica de búsqueda de la conocida como voluntad de la Ley cumple un papel importante -pues, al fin, se trata de decidir si dos normas concurren sobre la misma materia y si una desplaza a la otra- el llamado canon de la totalidad o del sistema, en cuanto instrumento técnico previsto en el artículo 3 del Código Civil, que posibilita la recíproca iluminación del significado de cada precepto, poniéndolo en relación con su contexto, esto es, con el núcleo o sistema al que pertenece y en el que se organiza y articula. Se ha dicho con razón que toda "interpretatio legis" implica una "interpretatio iuris"”. De forma más categórica se ha pronunciado el TSJ de las Islas Canarias al advertir, en Sentencia 136/2007, de 2 de marzo (recurso núm. 327/2002, ECLI ES:TSJICAN:2007:847), “ante algún tímido atisbo de planteamiento contrario, que el antecedente histórico no es argumento de recibo, cuando de lo que se trata es de determinar si ese antecedente resulta desvirtuado por la regulación nueva”.

${ }^{73}$ En este sentido, véase la Sentencia del TS de 27 de diciembre de 1988 (ECLI ES:TS:1988:9278), en la que expresamente se indica que "para que pueda hablarse de derogación tácita de una norma por otra posterior de igual rango es necesario que exista contradicción clara y tajante entre ésta y la anterior, lo que aquí no ocurre. Pero es que, además el derecho administrativo es derecho del poder para la libertad,
} 
Determinar la concurrencia de estos requisitos no es, por tanto, una tarea fácil y deberá realizarse precepto por precepto y teniendo en cuenta, a la vez, múltiples factores y principios interpretativos. Además, no está exenta de problemas, ya que pueden surgir conflictos de todo tipo, como, por ejemplo, en relación con la primera máxima interpretativa que hemos enunciado anteriormente (la presunción de no derogación de las normas). Así, puede darse la posibilidad de que, en vía interpretativa, en aras de la búsqueda de conciliación de nuevos preceptos con anteriores, se pueda llegar a alterar el sentido más normal y aparente de la nueva norma, y el pretendido, en último término, por el legislador o la Administración al aprobarla. En este caso, parece que, aunque fuera posible la conciliación entre las normas debería de darse prioridad a lo que quiere indicar la nueva norma, antes que buscar, a toda costa, la conciliación entre los preceptos. Este tipo de incoherencias, todavía no resueltas por nuestra jurisprudencia, nos empuja a defender, todavía más si cabe, formas más concretas, determinadas y específicas de derogación que, básicamente, no dejen cabos sueltos.

\section{c. El juego de los principios de temporalidad, especialidad y jerarquía}

Otra cuestión controvertida es el juego, en caso de derogación indeterminada, de los principios de especialidad y jerarquía, que pueden alterar y suponer un elemento extra de confusión en relación con el criterio de temporalidad que, como hemos indicado, sirve como regla general en la resolución de conflictos de este tipo. En este aspecto, no cabe duda de que, si uno de los criterios en conflicto es el jerárquico, este será el que prevalezca. Sin embargo, cuando el conflicto se produce entre los criterios cronológico y de especialidad "no hay datos teóricogenerales ni jurídico-positivos que permitan afirmar una determinada solución como diáfana e indiscutible" ${ }^{74}$. Por lo que a este análisis respecta, uno de los aspectos más controvertidos es si podemos encontrarnos ante una norma general que, de forma tácita o indeterminada, derogue una norma especial anterior. $Y$ es que, aunque la regla general sea que en estos casos prevalece el principio de especialidad normativa sobre el criterio temporal ${ }^{75}$, encontramos pronunciamientos de nuestro más alto tribunal que expresamente permiten que a través de la derogación tácita se deroguen por parte de normas generales preceptos de normas especiales (por lo que entendemos que, por tanto, también se podrán derogar mediante disposiciones

por lo que, en caso de duda, hay que inclinarse por acceder a la apertura solicitada, porque así lo impone entonces el principio de libre mercado. (...) Y esto no es pura teoría, ni aspiración programática, sino mandato constitucional imperativo, hasta el punto de que el Tribunal Constitucional confirma esa forma de entender el derecho administrativo -carácter que tiene la normativa farmacéutica- al declarar el principio de interdicción de la interpretación “contra cives” en su sentencia de 30 de septiembre de 1985”.

${ }^{74}$ Díez-Picazo Giménez (1990: 350).

${ }^{75}$ En este sentido, nos remitimos al análisis de TARDío PATO (2003) sobre el juego de estos principios y sobre cómo la jurisprudencia ha resuelto las cuestiones que afloran entre ellos, en el que indica que "invocando incluso el aforismo latino generalia, especialia non derogat (STS, Contencioso, de 4 de octubre de 1983, RJ 1983\5067) o aplicando a la especialidad la previsión del artículo 2.2 del Código Civil, atrás citado, que da como resultado el principio general según el cual para que las disposiciones especiales puedan estimarse derogadas o abrogadas precisan bien de una expresa y nominativa derogación en una norma posterior de carácter general o la anulación por otra disposición posterior que tenga el mismo carácter especial (STS, Contencioso, de 18 de septiembre de 1984, RJ 1984\4562)”. 
derogatorias indeterminadas preceptos de normas especiales anteriores en el tiempo) ${ }^{76}$. En este aspecto, también habrá que tenerse también en cuenta que, en numerosas ocasiones, lo relativo de lo que es o no es "especial" hará que este carácter pueda ser atribuido a ambas leyes y que, por tanto, el solapamiento entre ambas y su potencial solución sean todavía más complicados ${ }^{77}$.

De cualquier modo, cuando se aplican todos estos principios, tal y como apuntábamos al inicio del presente trabajo y como también indica GASCÓN ABELLÁNN ${ }^{78}$, el problema que habitualmente se plantea es la posibilidad de que haya múltiples interpretaciones sobre el alcance de la derogación indeterminada, ya que "cada intérprete puede entender que concurre o no incompatibilidad normativa, por lo que casos sustancialmente idénticos recibirán en el ordenamiento soluciones distintas, salvo, naturalmente, la mitigación de este fenómeno que puedan producir los eventuales mecanismos unificadores de jurisprudencia”. También en caso de conflicto entre normas de distinto rango jerárquico, habrá ocasiones en que el/la juez/a tendrá competencia para declarar la invalidez de la disposición, pero, en caso de no ser así, también la discrecionalidad judicial puede dar lugar a soluciones diferentes ante casos sustancialmente idénticos.

\section{Conclusiones}

En este trabajo se realiza un estudio sistemático acerca de los distintos problemas que conlleva la inclusión de disposiciones derogatorias indeterminadas, entendidas como aquellas que no incluyen una enumeración cerrada de las normas que derogan, sino que remiten a un momento posterior al de la aprobación de dicha norma la determinación de la existencia de una contradicción y, por consiguiente, su efecto derogatorio. Estos preceptos, que se encuentran presentes en gran cantidad de las normas aprobadas en nuestro país, han sido criticados por nuestros tribunales, los dictámenes del Consejo de Estado y nuestra doctrina, que entienden que un mejor estudio del contexto normativo y una mayor concreción del ámbito de derogación de las normas es deseable y, además, posible. En este sentido, tal y como hemos visto, los problemas asociados a estas normas se encuentran vinculados, esencialmente, a 1), la vulneración de los principios de seguridad jurídica y publicidad de las normas que en numerosas ocasiones conllevan, como consecuencia de su falta de claridad, lo difícil de su interpretación y de que generan, por lo habitual, una incoherencia o inconsistencia normativa que deja en manos de la persona encargada de aplicar el derecho la tarea de detectarla y,

\footnotetext{
${ }^{76}$ Así, la Sentencia 863/2020, de 23 de junio, del TS (recurso núm. 655/2017, ECLI ES:TS:2020:1804) reconoce expresamente la posibilidad de que mediante una norma general se derogue de forma tácita una norma especial anterior: “(...) importa recordar que rechazó que la Ley 22/2006 sea una ley básica, ya que ella misma no se califica como tal, y descartó que su carácter especial hiciera prevalecer sus prescripciones frente al designio ordenador de una ley posterior que sí era básica --el Estatuto del Empleado Público-- y que, "sin excepciones, pretende establecer una ordenación unitaria respecto a determinadas funciones" “. En este mismo sentido, véase las Sentencias, también del TS, 869/2020, de 24 de junio (recurso núm. 730/2018, ECLI ES:TS:2020:2033), y de 27 de diciembre de 2013(recurso núm. 3147/2012, ECLI ES:TS:2013:6490).

${ }^{77}$ En este sentido, véanse las Sentencias 5789/2010, de 29 de septiembre, y 564/2010, de 29 de septiembre, de la Sala de lo Civil del TS, mencionadas anteriormente.

${ }^{78}$ GASCÓn Abellán (1994, p. 856).
} 
posteriormente, dar preferencia a una norma frente a la otra (cuestión que conlleva, además, dejar en manos del intérprete jurídico una cuestión que debería ser resuelta por el legislador, en atención a los límites constitucionales de la potestad jurisdiccional ex art. $117 \mathrm{CE}$ ); 2), los efectos que su inclusión supone que, según hemos mantenido, son equivalentes a los de la derogación tácita; y, 3), la forma en que nuestros tribunales resuelven los conflictos que se dan respecto de la interpretación de este tipo de cláusulas.

Una vez sistematizados y analizados estos problemas, resta decir que entendemos que el conflicto que esencialmente subyace a este fenómeno es determinar si la aparición constante de este tipo de preceptos es positiva, en atención a que nunca está de más reiterar y recordar que las normas que aparecen en la disposición derogatoria expresa no son un numerus clausus no hemos logrado identificar ningún motivo diferente a este a favor de su mantenimiento-; o no, por suponer una "invitación" al legislador a no identificar correcta y exhaustivamente todas las normas que la nueva normativa derogará y porque permitir su uso y fomentarlo puede generar incentivos a que se legisle peor. Y que, según el peso que se dé a cada uno de estos argumentos, se podrá defender una u otra posición respecto de su uso.

Aquí, tal y como hemos desarrollado a lo largo de este trabajo, nos decantamos por la segunda opción, en atención a dos elementos. En primer lugar, a las numerosas evidencias detectadas sobre la falta de rigor de los poderes ejecutivo y legislativo a la hora de elaborar las disposiciones derogatorias que aparecen en todo tipo de normas. Y, en segundo lugar, a que entendemos que su eliminación contribuiría a que las personas encargadas de la redacción de los textos normativos procediesen a una mejor fijación aquellas que deben entenderse derogadas con la entrada en vigor del nuevo texto -algo que debería ser una tarea relativamente fácil de realizar con los actuales medios tecnológicos si se elaborase un estudio cuidadoso y atento de los antecedentes legislativos previo a la elaboración de la norma-. Esta interpretación viene además reforzada por las líneas interpretativas fijadas por nuestros tribunales en relación con la no reviviscencia de las normas derogadas mediante la derogación tácita, que las cláusulas derogatorias expresas no son, con carácter general y salvo que prevean explícitamente lo contrario, una enumeración numerus clausus de las normas que pierden su vigencia, y, finalmente, con el principio de presunción de no derogación de los preceptos que no estén expresamente derogados. Por estos motivos, así como por la importancia que tiene mejorar la seguridad jurídica y tratar de eliminar de nuestro ordenamiento jurídico toda normativa obsoleta y mejorar así su coherencia, orden y sistematicidad; nos decantamos aquí por un cambio en nuestra cultura normativa en el que se rechace -o incluso, elimine- la existencia (y continua expansión en el uso) de este tipo de cláusulas.

\section{Bibliografía}

Josep Aguiló Regla (1992), “Derogación, rechazo y sistema jurídico”, Doxa, 11, págs. 263-280.

Josep Aguiló Regla (1994), “La derogación en pocas palabras”, Anuario de Filosofía del Derecho, XI, págs. 407-418. 
Carlos E. AlChourRón y Eugenio Bulygin (1991), Análisis lógico y Derecho, Centro de Estudios Constitucionales, Madrid.

Ricardo Almeida GonZÁlez (julio de 2016), Red Internacional de Evaluación de Políticas Públicas. Obtenido de La Calidad Normativa y la nueva Ley de Procedimiento Administrativo en España: https://www.redinternacionalevaluacion.com/ricardo-almeida-leyes.

Alessandro ANDRONIO (1997), “Peculiarità nei fenómeno abrogativi pel periodo più recente”, págs. 109-137, en Ugo DE SIERVo (coord.), Osservatorio sulle fonti, Torino.

Andrés BoIX PaloP (2004), Las convalidaciones legislativas, Iustel Publicaciones, Madrid.

Andrés BoIX PALOP y Claudia GIMENo FERNÁNDEZ (2020), La mejora de la calidad normativa, PUV, València.

Dolors Canals Ametller (ed.) (2016), Datos. Protección, Transparencia y Buena Regulación, Documenta Universitaria.

Luis. M. a DíEZ-PiCAZo GimÉnez (1990), La derogación de las leyes, Civitas, Madrid.

Gabriel DoméneCh PASCUAL (2002), La invalidez de los reglamentos, Tirant Lo Blanch, Valencia.

Gabriel DomÉNECH PASCUAL (2017), "Las irregularidades no invalidantes desde una perspectiva económica”, págs. 151-170, en Fernando LÓPEZ RAMÓN y Francisco VILLAR Rojas (coords.), El alcance de la invalidez de la actuación administrativa: actas del XII Congreso de la Asociación Española de Profesores de Derecho Administrativo, Instituto Nacional de Administración Pública, Madrid.

Antonio Eduardo EmBiD Tello (2019), “Calidad normativa y evaluación ex-post de las normas jurídicas”, Revista General de Derecho Administrativo, 50.

Ezra FRIEDMAN y Abraham L. WiCKeLgRen, “A New Angle on Rules versus Standards”, American Law and Economics Review, págs. 499-549.

Pilar García-Escudero MÁrquez (2005), "Nociones de técnica legislativa para uso parlamentario”, Revista Parlamentaria de la Asamblea de Madrid, (13), págs. 121-164.

Javier GaRCía Luengo (2002), El principio de protección de la confianza en el Derecho administrativo, Civitas, Madrid.

Marina GASCÓN ABELLÁN (1994), “Cuestiones sobre la derogación”, DOXA, 15-16, págs. 845-859.

Claudia GIMENO FERNÁNDEZ (2018), La qualitat normativa al País Valencià. Propostes per a un nou model de producció i avaluació de les nostres normes, Fundació Nexe, València.

Ricardo GUARINONI (2006), “Derogación y después”, Isonomía - Revista de teoría y filosofía del derecho, 24, págs. 77-91. 
Riccardo GUASTINI, (1987) “In tema di abrogazione”, en Claudio LuZZATI (coord.) L'abrogazione delle leggi. Un dibattito analítico, 1987, Giuffrè, Milán.

Victoria ITURRALDE SESMA (2002), “Derogación innominada, acto de habla y de satisfacción condiciones”, Anuario de Filosofía del Derecho, 19, págs. 357-375.

Louis KAPLOW (1992), "Rules versus Standards: an Economic Analysis”, Duke Law Journal, 42, págs. 557-629.

Russell B. КововкIN (2000), "Behavioral Analysis and Legal Form: Rules vs. Standards Revisited”, Oregon Law Review, 79 (1), págs. 23-60.

Fernando LÓPEZ RAMÓN (2018), "La calificación de los vicios de los reglamentos”, Revista de Administración Pública, 205, págs. 13-48.

Pedro Mercado Pacheco (2013), "Calidad de la Ley, Evaluación de Impacto Normativo y Argumentos Económicos”, Anales de la Cátedra Francisco Suárez, 47, págs. 85-108.

Juan S. MoRA-SANGUinetTi (2019), “La “complejidad” de la regulación española ¿cómo medirla? ¿qué impacto económico tiene?”, Información Comercial Española: Revista de Economía, 907, págs. 145-162.

José Ramón Rodríguez CaRbajo (2015), “El Proyecto de Ley del Procedimiento Administrativo Común de las Administraciones Públicas (la ley del procedimiento electrónico)", Actualidad Administrativa, 10.

Ramón SÁnChez-Puente, Fe Bueno RodríGueZ y Andrea GarCía VidAL (2019), “La evaluación ex ante. Una visión de la Oficina de coordinación y calidad normativa”, Información Comercial Española, págs. 23-36.

Juan Alfonso Santamaría PAStor (2016), "Un nuevo modelo de ejercicio de las potestades administrativas”, Revista Española de Derecho Administrativo, 175, págs. 31-55.

José Antonio TARDÍO PATO (2003), “El principio de especialidad normativa (lex specialis) y sus aplicaciones jurisprudenciales”, Revista de Administración Pública, 162, págs. 189-225.

Tomás VIDAL MARTíN (2013), “Técnica legislativa, inserción de la norma en el ordenamiento jurídico y Tribunal Constitucional”, Teoría y Realidad Constitucional, 31, págs. 323-350.

Bernhard WALTL y Florian MATTHES (2014), "Towards Measures of Complexity: Applying Structural and Linguistic Metrics to German Laws”, Jurix: International Conference on Legal Knowledge and Information Systems, Krakow. 


\section{Anexo. Cuantificación del uso de las cláusulas derogatorias indeterminadas}

\begin{tabular}{|c|c|c|c|c|c|c|c|c|c|c|c|c|c|c|c|c|c|c|c|c|}
\hline & \multicolumn{5}{|c|}{ Leyes orgánicas } & \multicolumn{5}{|c|}{ Leyes ordinarias } & \multicolumn{5}{|c|}{ Decretos legislativos } & \multicolumn{5}{|c|}{ Decretos-ley } \\
\hline $\begin{array}{c}\text { Fecha de } \\
\text { disposición }\end{array}$ & Total & $\begin{array}{c}\text { Total } \\
\text { con } \\
D D^{79}\end{array}$ & $\begin{array}{c}\text { Contiene } \\
D D I^{80}\end{array}$ & $\begin{array}{l}\text { \% sobre } \\
\text { el total }\end{array}$ & $\begin{array}{c}\% \text { sobre } \\
\text { total } \\
\text { con } D D\end{array}$ & Total & $\begin{array}{c}\text { Total } \\
\text { con } \\
D D\end{array}$ & $\begin{array}{c}\text { Contiene } \\
\text { DDI }\end{array}$ & $\begin{array}{l}\text { \% sobre } \\
\text { el total }\end{array}$ & $\begin{array}{c}\% \text { sobre } \\
\text { total } \\
\text { con } D D\end{array}$ & Total & $\begin{array}{c}\text { Total } \\
\text { con } \\
D D\end{array}$ & $\begin{array}{c}\text { Contiene } \\
\text { DDI }\end{array}$ & $\begin{array}{l}\text { \% sobre } \\
\text { el total }\end{array}$ & $\begin{array}{c}\% \text { sobre } \\
\text { total } \\
\text { con } D D\end{array}$ & Total & $\begin{array}{c}\text { Total } \\
\text { con } \\
D D\end{array}$ & $\begin{array}{c}\text { Contiene } \\
\text { DDI }\end{array}$ & $\begin{array}{c}\% \\
\text { sobre } \\
\text { el total }\end{array}$ & $\begin{array}{c}\% \\
\text { sobre } \\
\text { total } \\
\text { con } D D\end{array}$ \\
\hline 1999 & 15 & 6 & 3 & 20 & 50 & 55 & 23 & 22 & 40 & 95,65 & 1 & 1 & 0 & 0 & 0 & 22 & 4 & 2 & 9,09 & 50 \\
\hline 2000 & 16 & 9 & 8 & 50 & 88,89 & 14 & 7 & 5 & 35,71 & 71,43 & 5 & 5 & 5 & 100 & 100 & 10 & 6 & 5 & 50 & 83,33 \\
\hline 2001 & 12 & 7 & 6 & 50 & 85,71 & 25 & 12 & 9 & 36 & 75 & 1 & 1 & 1 & 100 & 100 & 16 & 2 & 2 & 12,50 & 100 \\
\hline 2002 & 10 & 5 & 4 & 40 & 80 & 53 & 37 & 22 & 41,51 & 59,46 & 1 & 1 & 1 & 100 & 100 & 10 & 2 & 2 & 20 & 100 \\
\hline 2003 & 20 & 5 & 3 & 15 & 60 & 62 & 42 & 39 & 62,90 & 92,86 & 0 & 0 & 0 & - & - & 7 & 1 & 1 & 14,29 & 100 \\
\hline 2004 & 3 & 2 & 1 & 33,33 & 50 & 4 & 3 & 3 & 75 & 100 & 8 & 5 & 5 & 63 & 100 & 11 & 3 & 2 & 18,18 & 66,67 \\
\hline 2005 & 6 & 2 & 2 & 33,33 & 100 & 30 & 11 & 9 & 30,00 & 81,82 & 0 & 0 & 0 & - & - & 16 & 2 & 2 & 12,50 & 100 \\
\hline 2006 & 8 & 7 & 5 & 62,50 & 71,43 & 44 & 26 & 23 & 52,27 & 88,46 & 0 & 0 & 0 & - & - & 13 & 7 & 5 & 38,46 & 71,43 \\
\hline 2007 & 16 & 9 & 5 & 31,25 & 55,56 & 56 & 41 & 36 & 64,29 & 87,80 & 2 & 2 & 1 & 50 & 50 & 11 & 2 & 2 & 18,18 & 100 \\
\hline 2008 & 2 & 0 & 0 & - & - & 4 & 2 & 2 & 50 & 100 & 2 & 2 & 2 & 100 & 100 & 10 & 2 & 2 & 20 & 100 \\
\hline 2009 & 3 & 2 & 1 & 33,33 & 50 & 29 & 19 & 17 & 58,62 & 89,47 & 0 & 0 & 0 & - & - & 14 & 4 & 4 & 28,57 & 100 \\
\hline 2010 & 9 & 3 & 2 & 22,22 & 66,67 & 44 & 33 & 14 & 31,82 & 42,42 & 1 & 1 & 0 & 0 & 0 & 14 & 9 & 9 & 64,29 & 100 \\
\hline 2011 & 12 & 5 & 3 & 25 & 60 & 38 & 24 & 24 & 63,16 & 100 & 3 & 3 & 3 & 100 & 100 & 20 & 14 & 12 & 60 & 85,71 \\
\hline 2012 & 8 & 2 & 2 & 25 & 100 & 17 & 13 & 8 & 47,06 & 61,54 & 0 & 0 & 0 & - & - & 29 & 14 & 13 & 44,83 & 92,86 \\
\hline 2013 & 16 & 9 & 5 & 31,25 & 55,56 & 27 & 19 & 17 & 62,96 & 89,47 & 1 & 1 & 1 & 100 & 100 & 17 & 10 & 10 & 58,82 & 100 \\
\hline 2014 & 8 & 2 & 2 & 25 & 100 & 36 & 29 & 25 & 69,44 & 86,21 & 0 & 0 & 0 & - & - & 17 & 6 & 6 & 35,29 & 100 \\
\hline 2015 & 16 & 10 & 9 & 56,25 & 90 & 48 & 35 & 32 & 66,67 & 91,43 & 8 & 8 & 6 & 75 & 75 & 12 & 4 & 4 & 33,33 & 100 \\
\hline 2016 & 2 & 0 & 0 & - & - & 0 & 0 & 0 & - & - & 1 & 1 & 1 & 100 & 100 & 7 & 2 & 2 & 28,57 & 100 \\
\hline 2017 & 1 & 0 & 0 & - & - & 12 & 5 & 5 & 41,67 & 100 & 0 & 0 & 0 & - & - & 21 & 12 & 10 & 47,62 & 83,33 \\
\hline 2018 & 5 & 2 & 1 & 20 & 50 & 11 & 4 & 3 & 27,27 & 75 & 0 & 0 & 0 & - & - & 30 & 15 & 15 & 50 & 100 \\
\hline 2019 & 3 & 1 & 1 & 33,33 & 100 & 5 & 3 & 1 & 20 & 33,33 & 0 & 0 & 0 & - & - & 17 & 7 & 6 & 35,29 & 85,71 \\
\hline TOTAL & 191 & 88 & 63 & 32,98 & 71,59 & 614 & 388 & 316 & 51,47 & 81,44 & 34 & 31 & 26 & 76,47 & 83,87 & 324 & 128 & 116 & 35,80 & 90,63 \\
\hline
\end{tabular}

Fuente: elaboración propia a partir de datos procedentes del BOE.

${ }^{79}$ Estos apartados sistematizan el total de normas que presentan disposiciones derogatorias.

${ }^{80}$ Estos apartados sistematizan el total de normas que presentan una disposición derogatoria indeterminada. 